(Aus dem physiol. Institut der k. k. Hochschule für Bodenkultur in Wien.)

\title{
Beiträge zur Physiologie des Menschen im Hochgebirge.
}

Dritte Mitteilung ${ }^{1}$ ).

Über die Einwirkung von Alkohol anf die Steigarbeit. Von

\section{A. Durig.}

\section{Versuchsplan und Überblick über das Bekannte.}

Die gewaltige Literatur über die Wirkungsweise des Alkohols, die vielfach ganze und halbe Laien zu Urhebern hat, baut sich eigentlich nur zu einem relativ geringen Teil auf exakt wissenschaftlicher Forschung auf; die Aufzählung dieses letzteren Teiles allein füllt schon einen stattlichen Band von 500 Seiten aus. In dankenswerter Weise haben sich Abderhalden ${ }^{2}$ ) und seine Mitarbeiter dieser mühevollen Aufgabe unterzogen, so dass es heute viel leichter ist, einen Überblick über das positiv Geschaffene $\mathrm{zu}$ gewinnen und dies von der Summe wertloser Traktätlein, die keine Förderung bedeuten, zu trennen.

Das Register jener Arbeiten, die wir zu berücksichtigen haben, wird viel knapper, wenn wir uns jenen Abhandlungen zuwenden, die von rein physiologischen Standpunkten aus aufgebaut sind. Auch hier sind es wieder Fragestellungen, die mit unseren vorliegenden Versuchen in keinem direkten Zusammenhang stehen, so die Einwirkung des Alkohols auf ganz bestimmte Organe, wie z. B. auf die Funktion des zentralen Nervensystems oder auf jene des Herzens, weshalb wir von ihnen absehen wollen. Für uns steht wohl nur eine Frage im Vordergrund des Interesses, ob Alkohol ein Nahrungs-

1, Zweite Mitteilung Pflüger's Arch. Bd. 113 S. 213.

2) Bibliographie der gesamten wissenschaftlichen Literatur über den Alkohol. Urban and Schwarzenberg 1904. 
mittel ist, und $o b$ er andere Nährstoffe vertreten kann oder deren Zerfall zu verhindern vermag, und inwiefern eine Einwirkung des Alkohols auf die Muskelarbeit besteht, denn darüber, dass Alkohol ein Genussmittel ist und bleiben wird, wird wohl nie jemand gezweifelt haben. In der Frage nach dem Nährwert des Alkohols bei Körperruhe und Muskelarbeit liegt daher wohl der ganze Schwerpunkt der physiologischen Seite des Alkoholproblems. Wenn wir entscheiden könnten, ob Alkohol im Tierkörper verbrennt, und ob die durch seine Oxydation frei werdende Energie im tierischen Körper in nutzbare Energie umgewandelt werden kann oder nicht, und die Alkoholmengen $\mathrm{zu}$ berechnen vermögen, aus denen eine gewisse Arbeit geleistet werden kann, falls Alkohol überhaupt zur Leistung von Arbeit verwertet werdeu kann, dann wird es zeitgemässer sein zu entscheiden, ob solche Alkoholgaben, aus denen eine nennenswerte Grösse von Arbeit entspringen könnte, wegen der bekannten Giftwirkungen überhaupt noch in Betracht zu ziehen sind. Es ist selbstverständlich und oft genug betont, dass die Lösung dieses Problemes von weitgehendster praktischer Bedeutung ist, wissen wir doch, dass z. B. gerade in den Alpenländern von Holzarbeitern ganz unglaubliche Quantitäterı von konzentriertem Alkohol bei schwerer Arbeitsleistung und äusserst schmaler Kost genossen werden, ein Missbrauch, dessen Folgen sich dann in den so oft beschriebenen Schädigungen des Gesamtorganismus geltend macht und zu einem relativ früben Tod der Mehrzahl dieser Leute führt. Ganz ähnliche Verhältnisse finden sich übrigens auch in vielen grossen landwirtschaftlichen Betrieben, bei denen die Feldarbeiter überraschende Quantiläten von konzentriertem Alkohol neben etwas Brot vertilgen.

Der erste Teil der Frage, ob Alkohol im tierischen Organismus verbrennt, oder ob er zu einem grossen Teil in unveränderter Form oder als Aldehyd ausgeschieden wird, ist durch die Versuche von Strassmann ${ }^{1}$ ), Bodländer ${ }^{2}$, in neuester Zeit durch die umfangreichen Untersuchungen von Atwater und Benedict ${ }^{3}$ ) entscheidend dahin beantwortet worden, dass nur etwa $2 \%$ des zu-

1) Pflüger's Arch. Bd. 49 S. 315.

2) P flüger's Arch. Bd. 32 S. 398 (daselbst auch die ältere Literatur).

3) Memoirs of the National Academy of Sciences vol. 8. Sixth Memoir p. 233-297. Washington 1902 . 
geführten Alkohols den Körper unverbrannt durch Lunge und Harn verlassen, der ganze übrige Anteil desselben tatsächlich im Organismus aber zur Oxydation gelangt (l. c. S. 258 und S. 392).

Eine übersichtliche Zusammenfassung der Literatur und eine kritische Sichtung der durchgeführten Experimente, ob die als im Körper verbrannt ausgewiesenen Alkoholmengen in ihrem Energiewert dem Individuum zugute kommen oder ob diese Verbrennung nur den Zweck habe, das "Gift" zu oxydieren und zu eliminieren, rer Alkohol also als wertlos vom Organismus verworfen wird, hat Rosemann $n^{1}$ ) in einer Reihe von Arbeiten, die sich auf mühevoller (igener Arbeit aufbauen, vorgeführt; ebenso verdanken wir Caspari darüber wertvolle Aufschlüsse und eine gute Zusammenstellung der Ergebnisse $^{2}$ ). Von ganz abweichenden Gesichtspunkten aus hat Kassowitz in einer Reibe von Aufsätzen die vorliegenden Ergebuisse der wissenschaftlichen Forschung einer kritischen Besprechung unterzogen und sich dadurch mit den auf eigenen Experimenten aufbauenden Fachmännern in Gegensatz gestellt ${ }^{3}$ ).

Von anderen auf experimenteller Grundlage aufbauenden Arbeiten möchte ich nur unter Hinweis auf die Namen einiger Autoren Erwähnung tun, die in mühevollen Versuchen Beiträge zur Lösung der Frage lieferten und so ausser den erwähnten Forschern Rosemann und Caspari noch besonders $\mathrm{Clopatt,} \mathrm{Bjerre} \mathrm{und}$ Neumann nennen.

Das entscheidenste Wort haben aber die Versuche von Atwater und Benedict gesprochen, die am Respirationskalorimeter unter nleichzeitiger Bestimmung des Gesamtstoffwechsels durchgeführt sind und auch die Messung der Wärmeproduktion des Körpers gestatteten.

Atwater und Benedict haben einwandsfrei die Tatsache festgestellt, dass Alkokol im Ersatzversuch einen Teil der zugeführteı Nahrung nach dem Brennwert zu ersetzen vermag (1. c. S. 283).

Aus den Versuchen dieser wie auch der früheren Autoren entnehmen wir aber, dass mit der Sparwirkung des Alkohols typische Giftwirkungen verbunden sind, die sich schon in der anfünglichen

1) Pflüger's Arch. Bd. 94 S. 557 und Bd. 86 S. 307.

2) Fortschritte der Medizin Bd. 20 Nr. 33.1902.

3) Fortschritte der Medizin Bd. 21 Nr. 27 S. 913. P flüger's Arch. Bd. 90 S. 421. Allgemeine Physiologie Bd. 3 S. 420 ff. Pertes, 1904. 
Steigerung des Eiweisszerfalles nach Zufuhr von Alkohol am ungewöhnten Tier oder Menschen ausdrücken. Dasselbe besagt die Tatsache, dass das Absinken der ausgeschiedenen Kohlensäuremengen im Alkoholversuch gegenüber der Norm nicht so bedeutend ist, als man bei einem blossen Ersatz von Nahrungsstoffen durch Alkohol finden müsste, was darauf hindeutet, dass durch den Alkohol noch Nebenwirkungen ausgelöst werden, die Mehrausgaben gegenüber der Norm veranlassen.

E. Voit fasst in den "Ergebnissen" ${ }^{1}$ ) seinen Standpunkt demnach auch folgendermassen zusammen, indem er sagt: „Der Alkohol ist demgemäss in der Tat ein Nahrungsstoff, aber ein recht minderwertiger, denn seine eiweisssparende Wirkung wird durch seine giftigen Eigenschaften auf das Protoplasma wenigstens in der ersten. Zeit seiner Darreichung teilweise oder ganz aufgehoben, ja selbst überholt und ein Teil seiner fett- und kohlehydratsparenden Wirkung geht dadurch verloren, dass durch seine Nebenwirkungen der Organismus einen erhöhten Energiebedarf hat. Die in Form von Alkohol eingeführten Kalorien dürfen daher den in anderen Nahrungsstoffen (Eiweiss, Fett und Kohlehydrat) enthaitenen nicht als gleichwertig erachtet werden".

Diese untergeordnete Bedeutung, die daher für den Alkohol als. Nahrungsmittel bei der Ernährung des Menschen festgestellt ist, bringt auch Tigerstedt ${ }^{2}$ ) in seinem Lehrbuch in ganz ähnlichen. Worten zum Ausdruck, in denen er unter Festhaltung des Standpunktes, dass durch die Versuche, speziell jene von Atwater und Benedict, experimentell der Nachweis erbracht wurde, dass Alkohol nach seinem Verbrennungswerte Fett und Kohlehydrat zu ersetzen vermöge, also im St offwechselversuch mit seinem vollen Brennwert in Rechnung gezogen w erden muss, bei der normalen Ernährung des Menschen nur eineganz unbedeutende Rolle spielen kann, indem jene Alkoholmenge die ein nicht gewöhnter Mensch geniessen kann, ohne Vergiftungssymptome zu zeigen, nur etwa $4-7 \%$ des täglichen Kalorienbedarfes $\mathrm{zu}$ decken vermag.

Es ist also der Beweis, dass Alkohol im Körper verbrannt wird und, der Nahrung zugelegt, eine geringe Menge eines anderen Nahrungs-

1) Ergebnisse der Physiologie Bd. 1 S. 701. 1902.

2) Physiologie des Menschen, 3. Aufl., S. 128. 1905. 
- mittels im Tagesbedarf isodynam vertreten könne (wenn wir die allergünstigsten Verhältnisse zugrunde legen), theoretisch von höchstem Interesse, praktisch jedoch fast bedeutungslos, solange wir annehmen müssen, dass jene Mengen von Alkohol, die zur Verwertung im Körper herangezogen werden können, so geringe sind, und durch die von Voit gekennzeichneten und auch sonst schon vielfach betonten Mehrausgaben noch in ihrem, dem Körper zugute kommenden Wert wesentlich eingeschränkt werden.

So klar die Verhältnisse für den Umsatz im Menschen liegen, der keine grössere Arbeit leistet, so wenig wissen wir über den Einfluss von Alkohol auf die Arbeitsleistung. Es ist dies eine Frage, die besonders für die ländliche Arbeiterbevölkerung in Betracht kommt, da von dieser konzentrierter Alkohol in grösseren Dosen genossen und als Nahrungsmittel augesprochen wird, während wohl keiner der verpichtesten Trinker, sei es auch nur um sich vor sich selbst zu entschuldigen, an Ruhetagen den Alkohol als Nahrungsmittel zu sich nimmt, sondern ihn nur als Genussmittel betrachtet.

Es scheint mir daher die Tatsache, wie sich der Alkohol bei der. Leistung von Arbeit verhält, in der ganzen Beurteilung der praktischen Seite der Alkoholfrage von viel einschneidenderer Bedeutung zu sein als jene des Alkoholgenusses beim ruhenden oder wenig arbeitenden Menschen, und eine Entscheidung darüber, ob für die Muskelarbeit ein Teil von Alkohol ausgenutzt werden könne, wird ganz besonders bei solchen Personen zu suchen sein, bei denen wir eine Gewöhnung an die Giftwirkung voraussetzen können, so dass Alkoholmengen in Betracht kommen, die ihrer Menge nach einen nennenswerten Beitrag zu den Ausgaben des Körpers liefern könnten.

Wenn aus den vorerwähnten Versuchen feststeht, dass Alkohol und zwar als isodynamer Ersatz von Kohlehydrat und Fett verbrannt werden kann, so ist bei grosser Arbeit die Nebenausgabe für etwas mehr Wärmeausgabe und für überschüssige Muskelaktionen, die im Versuch mit wenig Arbeit in die Augen springen, sicher nicht als so bedeutungsvoll zu erwarten und mehr in den Hintergrund gedrängt, auch der anfängliche Eiweisszerfall, der ohnedies später verschwindet, wird bei der an Alkohol gewöhnten Person überhaupt nicht vorhanden sein. Es ist der Theorie nach also kein Hindernis zu erwarten, das dem im Wege steht, dass Alkohol auch bei Muskelarbeit eine isodyname Menge von Kohlehydrat zu vertreten vermag, und seinem Brennwert nach direkt oder indirekt für die Leistung 
von Arbeit herangezogen werden kann, oder man müsste von vornherein auf dem Standpunkt stehen, dass Alkohol ein Gift ist, und als solches sich nicht im Körper als brauchbar erweisen könne.

Es liegt daher die Fragestellung bezüglich der Muskelarbeit also so, ob überhaupt bei dieser Alkobol verbrannt wird und dadurch ein Teil von Nährmaterial erspart wird, was nach den Ergebnissen der Atwater'schen Versuche eigentlich fast selbstverständlich erscheint; denn es ist nicht anzunehmen, dass Alkohol, der im „Ruheversuch" Atwater's, in dem während der Hälfte des Tages doch leichte Arbeit geleistet wurde, wie sie auch der untätige Mensch leisten muss, isodynam sparend wirkte, dies bei zehnmal grösserer Arbeit nicht mehr tun soll, so dass ein prinzipieller Unterschied in den Oxydationsprozessen bei grösserer und geringerer Arbeit bestehen müsste. Im weiteren wird dann zu entscheiden sein, in welchem Verhältnis die nutzlosen Mehrausgaben bei der Arbeitsleistung nach Alkoholgenuss zu der aus dem Alkohol bezogenen Energie steht, wie die Frage zu erörtern sein wird, ob durch die Giftwirkung des Alkohols die Ausnützung der übrigen, aus der Verbrennung von Nahrungsmitteln entstammenden Energie eine geänderte geworden ist.

Fassen wir die praktisch am meisten verwertbare Seite der Wirkung von Alkoholzufuhr auf die Muskelarbeit ins Auge, so dürfte der Schwerpunkt also wohl nicht darin zu suchen sein, ob sich durch die Verbrennung von Alkohol direkt Muskelarbeit leisten lasse, oder ob er sparend auf andere Nahrungsmittel eingewirkt habe, die sonst. für die Leistung der Muskelarbeit zur Oxydation herangezogen wurden, sondern es wird der zweite Teil der Fragestellung der viel bedeutsamere sein, wenn wir die Mengen von Alkohol berücksichtigen, die überhaupt für die Leistung von Arbeit im äussersten Falle zur Verfügung gestellt werden können.

Die Entscheidung, ob aller resorbierter Alkohol direkt oder indirekt für die Leistung von Muskelarbeit ausgenützt werden kann, wird auch auf alle Fälle eine recht schwierige sein, dagegen führt der viel einfachere Weg viel leichter zum Ziel; es wird sich nicht allzuschwer festlegen lassen, ob überhaupt Alkohol in die Ausgaben bei der Leistung einer Arbeit einbezogen wird und ferner, unter welchem Nutzeffekt die aus der Gesamtverbrennung entstandene Energie dabei in Arbeit umgewandelt werden konnte. Zur Lösung der Frage nach der Alkoholwirkung sind wir daher nicht auf jene Zeit allein angewiesen, in der der Alkohol seine Sparwirkung entfaltete, sondern 
wir hätten hauptsächlich zwei Perioden voneinander zu trennen und einerseits jene Zeit für sich zu untersuchen, in der der Alkohol au Stelle eines Nahrungsmittels verbrannte, also eventuell bei der Arbeit andere Stoffe sparte, anderseits zu prüfen, wie sicb die Verhältnisse dann gestalten, wenn wir annehmen können, dass der sich rasch oxydierende Alkohol bereits verausgabt worden sei und direkt an den Vorgängen der Verbrennung nicht mehr beteiligt ist, also seine Sparwirkung bereits vorher entfaltet hat.

Die letztere Untersuchung schien als erste sehr einfach und auch sicher eindeutig zu einem Ziel zu führen, sie musste wenigstens einen Teil der Frage der Lösung zuführen und einen Einblick in die Verhältnisse gewähren, der dann das weitere Eindringen erheblich erleichtern sollte. Dies bildete den Vorwurf der vorliegenden Untersuchung; die Ergebnisse der Versuche, die ich unter der Voraussetzung anstellte, es sei die Hauptmenge, wenn nicht die ganze Menge der zugeführten geringen Alkoholdosis bereits in zwei Stunden verbrannt, belebren uns, wie wir im folgenden sehen werden, allerdings in anderer Weise, so dass meine Anschauungen sich seit der Zeit, in der die Versuche durchgeführt wurden und ein Ueberblick über die zahlenmässigen Ergebnisse noch nicht vorlag, wesentlich ändern mussten, was mir geradezu als wertvoll erseheint, da dadurch ein suggestiver Einfluss auf das Zustandekommen der Resultate ausgeschlossen wird.

Fassen wir in der Voraussetzung, dass der Organismus die für ihn gewöhnteste und daher auch für die Untersuchung geeignetste Form der Arbeit, bei der grosse Muskelgruppen in Aktion treten, die Steigarbeit, ähnlich wie eine Maschine leistet, an der wir Effekt und Wirkungsgrad prüfen, den Vergleich ins Auge zwischen dem Unterschied der Leistung von Arbeit nach vorhergegangenem Alkoholgenuss oder ohne solchen, so muss die Untersuchung des Gaswechsels und damit des Energieumsatzes bei der Steigarbeit ergeben, mit welchem Wirkungsgrad die Maschine, deren Verhalten wir bei gewöhnlicher Feuerung genau kennen, dann arbeitet, wenn wir sie einige Zeit mit Alkohol heizten und nun wieder, nachdem dieser verbrannt ist, zur normalen Feuerung zurückkehren. Wir werden daraus erkennen können, ob und in welchem Umfang sie bei diesem Zwischenregime Schaden gelitten habe. Finden wir in der folgenden Kontrollbestimmung keine Änderung von Wirkungsgrad und Fffekt, dann ist die Frage, wie die Maschine während der Alkoholfeuerung 
gewirkt habe, die naheliegende, und dann würde ferner zu entscheiden sein, wie der Preis des Alkohols als Feuerungsmittel sich gegenüber der gewöhnlichen Anheizung unter Berücksichtigung der gemessenen Leistungen verhalten hat.

Wenn sich aus dem Vergleich des Umsatzes für gleiche Leistungen und der Grösse der Leistung in der Zeiteinheit ein Nachteil für die Versuche ergeben sollte, in denen Alkohol genossen, vorher aber bereits verbrannt war, so musste diese zu berechnende Mehrausgabe von dem in der Vorperiode verausgabten Brennwert des Alkohols als Verlust durch Mehrausgabe in Abzug gebracht werden, so dass dann nur der erübrigte Rest im höchsten Falle, als für die Leistung einer nutzbaren Arbeit in Betracht kommend, zu berücksichtigen ist. Sollte sich dieser Wert als unverhältnismässig klein ergehen, so ist auch die Prüfung der Verbrennungsvorgänge bei Arbeitsleistung nach Alkoholgenuss im Hinblick auf die praktisch verwertbare Seite der Frage obne Bedeutung, da dann ein nennenswerter Erfolg für die Leistung länger dauernder Arbeit durch Alkoholgenuss ausgeschlossen ist, selbst wenn dieser in der Periode, in der er tatsächlich zur Verbrennung gelangte, in seiner Gesamtheit zur Leistung von Arbeit verwendet worden wäre. Dies ist der Grund, warum ich aus der einfachen Fragestellung, die den vorliegenden Versuchen zugrunde lag, und unter einfacher Methodik hoffen konnte, in das nicht so gut zugänglich scheinende Hauptthema Einblick gewinnen zu können und Direktionen für die weitere Bearbeitung desselben zu gewinnen.

Atwater und Benedict sind, soweit mir die Literatur bekannt ist, die einzigen, die den Stoffwechsel bei Muskelarbeit unter der Einwirkung des Alkohols genawer untersuchten; ich sehe dabei vorläufig von dem noch $z u$ besprechenden grundlegenden Versuch Chauveaus ab.

Trotz einer bewundernswerten Fülle von Geist und Arbeit, die die beiden Autoren auch für die Erforschung des Einflusses von Alkohol auf die Muskelarbeit aufgewendet haben, beurteilen sie ihre Resultate, so exakt wie diese gewonnen sind, mit ebensolcher Präzision, indem sie anführen, dass sie den Beweis dafür, ob Alkohol für die Leistung von Muskelarbeit zweckmässig verbrannt werde oder nicht, nicht zu erbringen vermögen, so sehr sie auch der Wahrscheinlichkeit Raum geben, dass Alkohol ähnlich wie Fett und Kohlehydrat für diese herangezogen werden könne. Die Verfasser schreiben S. 283:

"The utilization of the energy of the whole ration was slightly 
less economical with the alkohol than with the ordinary diet, especially when the subjects were at hard muscular work, but the difference in favor of the ordinary food was very small indeed, bardly enough to be of practical consequence. From this it follows that the energy of the alkohol was utilized very nearly or quite as well as that of the other fuel ingredients which it replaced.

That the alkohol contributed its share of energy for muscular work is a natural hypothesis and very probable, but not absolutely proven. The hypothesis that the energy of the alkohol was not so used, is not called for as an explanation of any fact observed in these experiments.

It should not be forgotten that the desirability of alkohol as a part of a diet for muscular work is not decided by the narrower questions here discussed. There is a very essential difference between the transformation of the potential energy of alkohol into the mechanical energy of muscular work and the advantage or disadvantage of alkohol in the diet of people engaged in muscular labor."

Ein Überblick über die Methodik und das Verhalten der Versuchsperson in den Experimenten lässt eine Unsicherheit in der Beurteilung der Resultate der Experimente wohl begründet erscheinen, wenn auch aus den Angaben der Verfasser hervorgeht, dass die Versuchsperson bestrebt war, sich möglichst gleichartig in den einzelnen Versuchen $z \mathfrak{u}$ verhalten und die Tageseinteilung wie die Arbeiten, die die Versuchsperson durchzuführen hatte, streng vorgeschrieben waren.

Der Umsatz, den die Versuchsperson für die am Velociped geleistete und nach aussen übertragene Arbeit aufwies, ist gegénüber den Ausgaben, die derselbe Mensch im Kalorimeter in dem Versuche ohne Arbeitsleistung zeigte, eine recht kleiner, und ferner muss bedacht werden, dass die Arbeitsleistung der Versuchsperson, die nicht in Strom umgewandelt nach aussen vermittelt und dort gemessen.werden konnte, eine recht namhafte gewesen sein muss, was sich bereits aus den Anführungen der Verfasser selbst ergibt, die darüber (S. 281) schreiben:

"Differences in the activity of the subjects in the two classes of experiments. These differences are not easy to avoid. The man in the chamber may make more muscular effort on one day than on another in taking down his bed in the morning and in setting it up at night, or he may move about more in caring for the food and 
excretory products and weighing himself and the absorbers. In the work experiments there may be differences in the external muscular work despite the best efforts to make the amounts constant from day to day. These differences in muscular activity, though small, may effect the metabolism of matter and anergy".

Es ist also die grosse Dauer des Experimentes in diesem Falle infolge der Unterschiede in der nicht gemessenen Muskeltätigkeit nicht von Vorteil, denn wir können nicht ermessen, was durch trägeres Verhalten der Versuchsperson, die in 6 Dosen ungefähr $72 \mathrm{~g}$ Alkohol im Tage zu sich nahm, etwa an Arbeit gespart, andererseits an überschüssigen Bewegungen wieder verausgabt wurde, so dass die zwischen dem "Ruheexperiment" und dem "Arbeitsexperiment" gefundene Differenz an Kalorien nicht rein auf die Arbeitsleistung am Velociped bezogen werden kann. Ich möchte nur auf das in der vorigen Mitteilung angeführte hinweisen und dabei bemerken, wie bereits ganz geringe Einflüsse die Arbeitsleistung und den Verbrauch zu beeinflussen vermögen, die für uns kaum gefühlt werden, wie etwa beim Horizontalmarsch, der mit den Hantierungen der Versuchsperson etwa in eine Parallele zu stellen ist. Hier ist, wie in manchen Fällen überhaupt, das längerdauernde Experiment dem kürzeren nicht überlegen, sondern geradezu geeigneter, die Verhältnisse zu verwischen, wie ich dies auch an anderer Stelle anlässlich der Versuche über die Änderung des Sauerstoffverbrauchs durch den Sauerstoffgehalt der zugeführten Luft nachweisen konnte, wobei die längere Versuchsdauer durch Serien kurzdauernder Experimente ergänzt wurde.

Es ist nun ganz gut denkbar, dass die durch den Alkoholgenuss etwas weniger arbeitslustige Person manche Bewegung, die sie sonst ausgeführt hätte, unterliess, andere Arbeiten langsamer und mit geringerem Stoffverbrauch durchführte, wie wir dies später bei unseren Marschversuchen sehen werden, endlich aber auch umgekehrt eine Menge von Muskelarbeit mehr und mit anderem Effekt leistete, als dies obne Alkoholgenuss geschehen wäre. Alle diese Variablen häufen sich nun auf die geringe, von der Versuchsperson geleistete und nach aussen übertragene Arbeit, die zur Messung gelangte und deren Grösse wir im Verhältnis zu dem Energieumsatz bei der im Kalorimeter ausgeführten und nicht als Arbeit, sondern als Ausgabe in Form von Wärme bestimmten Bewegungen annähernd berechnen können. 
Durch die Untersuchungen von $\mathrm{Zuntz}$ und seinen Schülern, insbesondere von Loewy sowie durch Johannsson, wissen wir, dass der Betrag an Arbeit, der von einem nicht in absoluter Körperruhe sich befindenden Menschen geleistet wird, ein recht beträchtlicher ist. Versuchen wir diesen für die Versuchsperson EO. von Atwater und Benedict durch den Vergleich eines "Ruheversuches" ihrer Reihen mit dem wirklichen Ruhewert der Versuchsperson zu berechnen. Das Körpergewicht der Person, die sich den Versuchen 22 und 12 unterzog (EO.), finden wir mit $72,78 \mathrm{~kg}$ (13. März, Mittel siehe S. 332 Tab. 47) inklusive Kleidern für den Versuch 22 angegeben, den wir als Ruheversuch zugrunde legen wollen. Dieselbe Person weist an einem anderen Tage (S. 293 Tab. 4) 70,56 kg ohne Kleider und 74,19 $\mathrm{kg}$ mit Kleidern als Gewicht auf, so dass wir für unsere Berechnung wohl ganz berechtigt für EO. ein Nacktgewicht von rund $70 \mathrm{~kg}$ annehmen dürfen. Setzen wir nun unter Berechnung der Körperoberfläche der V'ersuchsperson den bekannten Wert von $11,2 \mathrm{~g} \mathrm{CO}_{2}$ per $\mathrm{m}^{2}$ und Stunde als Produktion bei absoluter Körperruhe ein, so ergibt sich eine Kohlensäureausscheidung pro Tag $11,2 \times 24 \times 2,089$, das ist $562,1 \mathrm{~g}$; dagegen liegt der im Versuch 22 selbst bestimmte Wert der täglichen Kohlensäureausscheidung mit 762,2 $\mathrm{g} \mathrm{CO}_{2}$ (aus dem Mittel des Versuchs S. 336 Tab. 3, Vers. 22) vor, so dass für die Muskelbewegungen, die als Arbeit. nicht gemessen wurden, inklusive Verdauungsarbeit eine Produktion von $762,2-562,1=200,1 \quad \mathrm{~g}_{2} \mathrm{CO}_{2}$ erübrigt. Stellen wir nun den "Ruheversuch" mit dem "Arbeitsversuch" in eine Parallele, so ergibt sich für Versuch 12 (Tab. CXX S. 390 und Tab. III S. 336) eine tägliche Kohlensäureausscheirung von $1263 \mathrm{~g} \mathrm{CO}_{2}$ im Mittel gegen den erwähnten Ruheversuch mit $762,2 \mathrm{~g} \mathrm{CO}_{2}$, so dass für die Leistung der ganzen Tagesarbeit $501 \mathrm{~g} \mathrm{CO}_{2}$ ausgeatmet wurden. Es stellt sich also die Kohlensäureausscheidung für die nicht als Arbeit bestimmte Tätigkeit der Muskulatur und für Verdauungsarbeit im Verhältnis zu der der Berechnung zugrunde gelecten, am Veloziped geleisteten Arbeit wie 501:200, was einem Wert von rund 40\% für die Ausgaben über den wahren Ruheverbrauch im "Ruheversuch" gegenüber der geleisteten und gemessenen Arbeit im Arbeitsversuch entspricht.

Betrachten wir dem gegenüber die Grösse der ganzen, gemessenen Tagesleistung, so ist diese an und für sich sehr gering. Wir entnehmen dies ans Tab. CXX S. 390 Works experinents Group 
D-F, für die sich im Mittel eine Tagesarbeit von 211 Cal., das ist rund 90000 Meterkilogramm ergibt, womit ich nur meine Arbeitsleistung in $2^{3 / 4}$ Stunden in den unten zu besprechenden Versuchen in Vergleich stellen möchte, die in der unvergleichlich kürzeren Zeit die doppelte Höhe von $192000 \mathrm{mkg}$ (siehe voriges Mittel, Tab. 13) erreichte.

Es ist demnach in der Tat schwer, aus den Atwater- und Benedict'schen Versuchen, was ja auch die Verfasser in ihrer präzisen Weise selbst tun, beweisende Momente für den Einfluss des Alkohols auf die Muskelarbeit abzuleiten, da einerseits die Grösse der gemessenen Arbeit im Vergleich zu den Ausgaben, die den wahren Ruhewert im Vergleichsruheversuch übertreffen, eine geringe ist, und anderseits die vollkommene Unsicherheit über die Mehroder Minderausgaben für diesen $2 / 5$ des gemessenen Arbeitswerts betragenden Posten einen Schluss auf die, für die Muskelarbeit selbst eingeleitete Verbrennung von Alkohol nicht mehr zu ziehen gestattet. Es erschwert aber auch der für die Produktion von gemessener Arbeit gegenüber der ganzen Tagesarbeit in Betracht kommende Rest von Alkohol eine derartige Bestimmung noch weiter. Die von der Versuchsperson Atwater's geleistete Arbeit forderte einen Aufwand von 1500 Cal., während die auf den Tag verteilte Alkoholmenge einem Brennwert von rund 500 Cal. entsprach. Nun ist der Verbrauch im Ruheversuch mit 2200 Cal. im Durchschnitt anzusetzen, somit auch das Verbältnis der für die Arbeit gegenüber der "Ruhe“ ausgegebenen Calorien ein ausserordentlich geringes (Ruhe zu Arbeit 1:9 in meinem Arbeitsversuchen, die am Schlusse besprochen werden sollen, hier nur $1: 1,7)$. Nun ist auf jeden Fall anzunehmen, dass sich der Brennwert des Alkohols in gleichem Masse auf die kleinere, oben berechnete Arbeit, die nicht als solche gemessen und nicht nach aussen übertragen wurde, verteilt habe, so dass ein Abstrich von $2 / 5$ von der zur Verfügung stehenden Alkoholmenge gemacht werden muss, der jedenfalls nicht der gemessenen Arbeit zugute kommen konnte, so dass für diese nur noch 300 Cal. zur Verfügung standen, von denen im günstigsten Falle nach dem von Atwater festgestellten Nutzwert nur $20 \%$, das ist $60 \mathrm{Cal}$. in Arbeit umgewandelt werden konnten. Wahrscheinlich werden wir aber richtiger rechnen, wenn wir annehmen, dass sich der Alkokol zu gleichen Teilen auf den Ruheverbrauch und auf die Arbeit verteilt habe; wir kommen dann zum Resultat, dass von der zur Verfügung stehenden Alkoholmenge 297,6 Cal. für die Deckung des „Ruhebedarfes" und 202,4 Cal. 
für die des Arbeitsbedarfes auf den ganzen Tag verteilt, in Verwendung gezogen worden sind und dann nur noch 40 Cal, für die Umwandlung in Arbeit bei der messbaren Arbeit verfügbar gewesen wären. In den dem grösseren "Ruheverbrauch" entsprechenden Anteil des Alkohols mit 297,6 ist natürlich auch der Aufwand an Alkohol für die kleine, ungemessene Arbeit einbezogen, auf die wir $\frac{2 \times 202,4}{5}=$ 80,9 Cal, an Alkoholverbrennung zu verlegen bätten, so dass dann 216,7 Cal. des Alkohols auf die Ruhe, 202,4 Cal. auf die gemessene Arbeit und 80,9 auf die ungemessene Arbeit entfallen wären und der zur Verfügung gestandene Alkohol auf alle drei Komponenten in ungefähr gleicher Weise verteilt wirken musste. Wenn wir nun nochmals das Bild vor Augen rücken, das uns das verschiedene Verhalten der Versuchsperson bei Alkoholgenuss wahrscheinlich machte, unter der Voraussetzung, dass ein Teil der Muskelbewegungen lebhafter, ein anderer weniger lebhaft ausgeführt worden sei, wieder andere ganz gefehlt haben, so muss es auch in bezug auf die Verbrennung des Alkohols selbst schwer sein zu sagen, hei welcher Tätigkeit er in grösserem Masse oder vielleicht gar nicht ändernd eingewirkt babe. Als musterhaft funktionierendes Präzisionsinstrument besagt uns das Kalorimeter zwar, dass der Alkohol in seinem Verbleib und in seiner Energieentwicklung im Respirationskalorimeter in seiner Gänze quantitativ verfolgt werden konnte, auch wenn Muskelarbeit geleistet wurde, aber einen Einblick in die spezielle Wirkung auf die Muskelarbeit konnte es nicht gewähren und wird es auch nie geben können, da die verschiedenen Wirkungen des Alkohols, die nach der Zeit, in der der Alkohol genommen wurde und in der nachher die Muskelarbeit folgte sowie auch während dieser selbst keinen Augenblick konstante, sondern stetig wechselnde sein müssen, wie dies aus den sofort zu besprechenden Ergographenversuchen und aus meinen Marschversuchen hervorgeht.

Trotzdem das Chauveau'sche Experiment am Hunde lange nicht mit jener Umsicht und einem so glänzend funktionierenden Apparat, wie es das Respirationskalorimeter von Atwater ist, durchgeführt wurde, so ist es für die Entscheidung der in Rede stehenden Frage samt allen Bedenken, die ihm entgegenzubringen. sind, doch bedeutungsvoll geworden. Das viel umstrittene Experiment mit dem $20 \mathrm{~kg}$ schweren Hund, der $48 \mathrm{~g}$ Alkohol erhielt und in einer Lauftrommel lief, wobei seine Kohlensäureausscheidung, 
wie cier zurückgelegte Weg und bei genau bekannnter Nahrung die Veränderung des Körpergewichtes bestimmt wurde, ist zu bekannt, um es ausführlich beschreiben zu müssen.

Ist immerhin der Einwand berechtigt, dass der Hund als ein Tier, das sonst Alkobol nicht zu konsumieren pflegt, nicht jenen Wert als Versuchsobjekt für die Frage besitzt, wie der an Alkoholgenuss gewöhnte Mensch, und ist auch die Dosis ron Alkohol, die dem Tier gegeben wurde, eine ganz ausserordentlich hohe, so ist das Resultat des Versuchs doch ein eminent wertvolles, dass trotz Leistung geringerer Arbeit und trotz gleichbleibender Zufuhr von Kalorien in der Nahrung, in der gegenüber dem Kontrollversuch ohne Alkohol eine isodyname Menge von Zucker durch die $48 \mathrm{~g}$ Alkohol crsetzt wurle, eine Abnahme des Körpergewichtes erfolgte. Verminderung der Leistung, die bei so bohen Dosen, bei denen das Tier betrunken war, allerdings nichts Überraschendes bietet, neben Vermehrung des Verbranchs sind die unter den Bedingungen des Chaveau'schen Versuches unumstösslich festgelegten Tatsachen.

Wenn durch die Ausführungen Ros emann' $\mathrm{s}^{1}$ ) die von anderer Seite unter unrichtiger Beurteilung des respiratorischen Quotienten aufgestellten Ansichten widerlegt wurden und auch die Ansicht Chauveau's in bezug auf die Verbrennung des Alkohols ihre Korrektur erfuhr, so haben dadurch die grundsätzlichen, von $\mathrm{Ch}$ a uveau festgestellten Tatsachen nichts an ihrer Bedeutung verloren. Allerdings wirl uns durch sie noch kein Einblick in die feineren Verhältnisse des Chemismus des Stoffwechsels gewährt, die für den Körper bei der Alkoholwirkung in Betracht zu ziehen sind.

I)amit wären aber auch unsere Kenntnisse über den Umsatz bei Muskelarbeit im Körper, soweit sie dureh Versuche gestützt sind, beleuchtet, wobei wir zur Erkenntnis gelangen, wie vieles in dieser Hinsicht noch $\mathrm{zu}$ schaffen ist.

In bezug auf den zeitlichen Verlauf der Alkoholwirkung geben uns die Versuche mit ergographischer Methodik bessere Aufschlüsse. Wie dies der Bequemlichkeit der Versuchsdurchführung und der Möglichkeit, rasch Resultate zu erzielen und sie schwarz auf weiss geschrieben sofort vergleichen zu können, entspricht, ohne dass man sich viel mit analytischer Arbeit zu plagen hätte, liegt eine ganze Reihe von Publikationen vor. Alle leiden mehr oder

1) Pflüger's Arch. Bd. 94 s. 558. 
minder an den Bedenken, die überhaupt gegen die ergographische Methodik erhoben wurden. Nichtsdestoweniger verdanken wir aber doch besonders den Arbeiten von Scheffer, von Hellsten und endlich den Untersuchungen von Schnyder und Frey recht wertvolle Beiträge zur Lösung dieser Frage. Scheffer arbeitete an einem Mosso'schen, Hellsten an einem Johannsson'schen Ergographen; beide legten besonderen Wert darauf, dass sehr zahlreiche Versuche, die unter möglichst gleichen Bedingungen angestellt sind, untereinander zum Vergleich gelangten und schickten daher eigene Übungsversuchsreihen voraus. Wenn auch die Versuche nur die Einwirkung des Alkohols durch Untersuchung der Änderung in der Arbeitsleistung eng begrenzter Muskelgebiete prüften, so konnten sie doch den Eintritt und den Verlauf der Wirkung in präziser Weise trennen, wogegen sie, wie sich dies bei ergographischen Versuchen überhaupt als undurchführbar herausgestellt hat, keine Angaben über den gleichzeitig vor sich gehenden Umsatz sowie über den Nutzeffekt machen konnten, unter denen die Arbeit geleistet wird.

Die Versuche Scheffer' ${ }^{1}$ ) sind zum Teil an dem Verfasser selbst durchgeführt, zum Teil betreffen sie Frösche. Letztere Beobachtungen sollten eine Kontrolle darüber ermöglichen, ob eine Autosuggestion in den Versuchen am Mensehen stattgefunden habe, sowie ergeben, inwieweit Nerv und Nervenendigungen am Zustandekommen der Erscheinungen beteiligt seien.

Scheffer ist selbst an geringen Alkoholgenuss gewöhnt. Er trinkt täglich 1 Glas Bier, so dass die Zufuhr von $10 \mathrm{~g}$ Alkohol in $100 \mathrm{~g}$ Wasser, um die es sich in seinen Versuchen handelte, für ihn eine gewiss nicht so grosse ist, dass man sagen könnte, sie würde die Menge, an die er gewöhnt ist, weit übersteigen; es war also das Eintreten eines Eiweisszerfalls um so mehr, als die Versuche durch lange Zeit fortgesetzt wurden, auf Grund der Alkoholdosis nicht zu erwarten. Immerhin beschreibt $\mathrm{S}$ ch effer aber doch, dass er nach Einnahme des Alkohols Wärmegefühl und geringere Arbeitslust empfunden habe. Reihen mit Alkoholgenuss wechselten mit Reihen ohne Alkoholgenuss, so dass eine Verschiebung der Resultate durch die Übung ausgeschaltet war. Seine Ergebnisse lauten dahin, dass der Genuss von Alkohol in geringen Mengen bereits nach 5 Minuten eine Steigerung der Arbeitsleistung auslöst und zwar sowohl am ermüdeten,

1) Arch. f. exper. Pathol, u. Pharmak. Bd. 44 S. 24.1900. 
wie am nicht ermüdeten Muskel, die etwa eine halbe Stunde andauert, um dann von einer Abnahme der Leistungsfähigkeit gegenüber der Norm gefolgt zu sein. Er vertritt dabei die Ansicht, dass der Alkohol eine deutliche Beeinträchtigung des Ermüdungsgefühls auslöst, was jedoch nicht allein als Ursache der Mehrleistung im Beginne der Alkoholwirkung angesehen werden dürfe.

Seine Untersuchungen am Frosch, die ihn in vollständige Übereinstimmung mit Kobert und Waller bringen, lassen ihn zur Anschauung kommen, dass durch den Alkohol zuerst eine Erhöhung, dann eine Verminderung der Erregbarkeit des Nervensystems zustande kommt, deren Wegfall durch das Curaresieren des Versuchstieres beweist, dass die Einwirkung des Alkohols auf die Muskulatur keine direkte, sondern nur durch Vermittlung des Nervensystems bedingt sei.

Auch die Versuche von Hellste $\mathbf{n}^{1}$ ) beanspruchen besondere Hervorhebung. Hellsten, ein für Schauturnen eingeübter Sportsmann von $92 \mathrm{~kg}$ Gewicht, stellte durch $2^{1 / 2}$ Monate ergographische Versuchsreihen unter Hebung grosser Gewichte an (bis zu $10000 \mathrm{mkg}$ im Tag, im Mittel 5-6000 mkg täglich). Auch er schickte eine Periode des "Trainierens" voran und achtete in seinen Versuchen besonders auf Ausschluss der Ermüdung, dabei war er bestrebt, sein ganzes Verhalten, Ernährung und Lebensweise während der Dauer der Versuche möglichst gleichartig zu gestalten. Sämtliche Versuche führte er bei geschlossenen Augen durch. Alkoholreihen schoben sich zwischen die Versuche ohne Alkohol (Normalversuche) ein. Die Alkoholdosen, die er benötigte, um sichere Erfolge einer Alkoholwirkung zu erzielen, liegen bei ihm ganz auffallend hoch $(80 \mathrm{~g}$ ! S. 37). Seine Resultate, die aus zahlreichen gut übereinstimmenden Versuchen gewonnen wurden, gehen dahin, dass Alkohol unmittelbar vor Begiun der Versúche genommen, die Leistungsfähigkeit anfänglich erhöht, doch folgt bald eine Reaktion, die bestimmt in 12 bis 40 Minuten eintritt und zu einem Absinken bis stark unter die Norm fübrt. Bei grösseren Dosen fand er die Wirkung früher, bei geringen später eintreten. Ein durchgehendes Charakteristicum der Alkoholversuche ist es, dass die geleistete Sekundenarbeit für die Periode der Alkuholversuche kleinere Werte aufweist als für die entsprechenden Normalversuche, und zwar auch in solehen Beobach-

1) Über den Einfluss von Alkobol, Zucker und Tee auf die Leistung des Muskels. Inaug.-Diss. Veit \& Co., Leipzig 1904. 
tungen, in denen die Arbeit in Meterkilogrammen (ohne Rücksicht auf die Zeit) grösser oder ebenso gross ist als in den Normalversuchen, eine Tatsache, auf die schon Kraepelin hinwies.

Die Form der Ergogramme wird ungleichmässiger, wenn vorher Alkohol genossen wurde; man sieht an ihnen Wellenformen als Zeichen dessen, „dass die Muskelkontraktion während der Dauer der Zusammenziehung nicht mit gleichförmiger Geschwindigkeit erfolgt" (1. c. S. 48). Zwei Stunden nach der Einfuhr von Alkohol ist die Wirkung oft bereits wesentlich im Zurückgehen begriffen oder kann schon verschwunden sein.

Die Grösse der Abnahme der Leistungsfähigkeit findet ihren Ausdruck in einer Verminderung der Arbeit im Alkoholversuch gegenüber dem Nơrmalversuch um 16 bezw. $17 \%$ (l. c. S. 40 u. 44).

Ausgedehnte Versuche über die Einwirkung des Alkohols auf die Muskelarbeit führte auch H. Frey aus ${ }^{1}$ ) (die erste Arbeit liegt mir nicht vor). Frey stellt die Grundsätze seiner ersten Arbeit, dass Alkohol auf den nicht ermüdeten Muskel einen schädlichen Einfluss ausübt, indem er dessen Arbeitsleistung herabsetzt, anderseits das Ermüdungsgefühl am ermüdeten Muskel vermindert, gegenüber den Einwänden, die gegen seine Ausführungen erhoben werden, nochmals fest, und führt neue Versuche an, aus denen hervorgeht, dass unter den Bedingungen, unter denen er arbeitete, die Zufuhr von Alkohol die Leistungsfähigkeit des ermüdeten Muskels auf längere Zeit wieder zu erhöhen vermag, und zwar besser als eine Zufuhr von Zucker (Taf. VII und S. 52), womit er sich in teilweisen Gegensatz zu dem bezüglichen Versuch von Hellsten setzt. Frey nimmt auf Grund seiner Ergebnisse an, dass Alkohol im Notfall sehr gut an Stelle einer Frholungspause treten könne, indem er schreibt: „Der Bergsteiger, der für die Notfälle ein kleines Quantum Alkohol auf seine Exkursion mitnimmt, handelt somit nicht unklug. Wenn ér bei starker Ermüdung die Wahl hat zwischen Alkohol oder einer längeren Ruhepause, wird er wohl das letztere wählen, ist aber keine Wahl mehr vorhanden und muss er unbedingt sofort vorwärts, dann wird er über das Gift herzlich froh sein . .." Ich erwähne diese Angabe Frey's ausdrücklich, obwohl sie mit meinen folgenden Versuchen in keinem so direkten Zusammenhang steht, da

1) Alkohol und Muskelermüdung. Eine kritische Studie. Deuticke, Wien und Leipzig 1903.

E. Pflüger, Archiv für Physiologie. Ba. 113. 
diese weder jemals an ermüdeter Muskulatur angestellt wurden, noch die Zeit sofort nach Einfuhr einer Dosis Alkohol betrafen, die wir als die Periode der Reizungswirkung bezeichnen können, um meine Stellung in der Frage zu präzisieren, damit etwa nicht aus den Ergebnissen meiner Versuche Schlüsse abgeleitet werden, die daraus nicht gezogen werden dürfen. Ist auch der Rückschluss von ergographischen Versuchen auf die Änderung, die die Gesamtleistungsfähigkeit eines Menschèn durch Alkoholgenuss erfährt, kein unbedingt zulässiger und nur durch eine gewisse Wahrscheinlichkeit gestützt, so teile ich doch die Ansicht Frey's in vollem Umfange und hoffe den exakten experimentellen Beweis für die Richtigkeit dieser Annahme einer Steigerung der Leistungsfähigkeit des ermüdeten Individuums in Bälde erbringen zu können, gleichzeitig aber auch die Veränderungen, die dabei im Stoffumsatz eintreten, gebührend kennzeichnen zu können. Die praktische Bedeutung, wie sehr eine im geeigneten Moment gegebene Dosis Alkohol als Peitsche zu wirken vermag, habe ich selbst nur zu deutlich an meinem verehrten Begleiter vor dem Aufstieg über den letzten Eishang, der zum Monte-Rosagipfel zieht, würdigen gelernt und auch sonst zu wiederholten Malen auf Touren an anderen beobachtet, obwohl ich selbst nie einen Tropfen Alkohol bei mir zu tragen pflege. Die Frage jedoch, ob diese letzte Arbeit auf Kosten des zugeführten Alkohols geleistet wird, ist dadurch nicht im mindesten gestreift, geschweige denn erledigt, denn es ist wohl unzweifelhaft, dass, wenn dieser Teil der spezifischen Wirkung des Alkohols, mag man sie nun Giftwirkung, erregende Wirkung, Wegschaffung von Hemmungen oder Betäubung des Ermüdungsgefühls nennen, vorüber ist, die andere Periode der Wirkung sich mit unfehlbarer Sicherheit einstellen wird, jene der weiteren Herabsetzung der Leistungsfäbigkeit. Man wird eines derartigen Reizmittels in manchen Fällen ebenso wenig entraten können wie etwa der Kampferinjektion, durch die ein erlahmendes Herz zu neuen kräftigen Kontraktionen auf kurze Zeit angeregt werden kann, wenn man sich dabei auch vollkommen bewusst ist, dass es nicht die Kalorien sind, die Kampfer bei seiner Verbrennung gibt, die das Herz zu einem weiteren Umsatz an Spannkraft veranlassen, die sonst nicht zustande käme.

Steht somit die erste These Frey's in vollkommener Übereinstimmung mit dem, was wir aus den übrigen Versuchen wissen, so sind die Versuche, die die Frage der Wirkung des Alkohols auf die 
ermüdete Muskulatur betreffen, in ihrer Deutung, wenn sie auch den Ergebnissen der experimentellen Feststellung vorgreifen, durch die Erfahrung so gut fundiert, dass die Annahme einer derartigen Wirkung einer vorübergehenden Steigerung an Leistungsfähigkeit ermüdeter Muskulatur durch Alkobolgaben, die in manchem Fall im Hochgebirge sogar lebensrettend wirken kann, vollauf begründet ist. Soviel über die Versuche Frey's, denen gegenüber manchen Angriffen mehr Gerechtigkeit widerfahren sollte, da sie trotz des einen oder anderen Einwandes, den man gegen deren Durchführung erheben kann, in ibren Grundsätzen, die sie festlegten, einen wertvollen tatsächlichen Bestand in der Kenntnis der Frage geliefert haben.

Eine vorübergehende Zunahme der Leistungsfähigkeit ${ }^{1}$ ) nach vorhergegangenen Alkoholdosen, die als Alkohol, Kognak, Marsala usw. gegeben wurden, beobachteten auch Lombard, Dastrée, Rossi, Tavernari, Kraepelin mit Oseretzkowsky und mit Glück u. a. Nach fast allen Autoren ist die anfängliche Zunahme von einer späteren Abnahme der Leistungsfähigkeit gefolgt. Eine etwas abweichende Versuchsmethodik liegt den S c h u m bu rg' schen Versuchen zugrunde, die in bezug auf den Alkohol allerdings etwas wenig zahlreich und auch untereinander nicht streng verglichen sind. Endlich wäre noch des reichen Versuchsmaterials von $S \operatorname{chnyder}{ }^{2}$ ) zu gedenken, der zu dem Resultat gelangt, dass Alkohol, in kleinen Mengen genossen, dann, wenn nach den individuellen Verhältnissen der Kraftvorrat eines Menschen erschöpft ist, eine günstige Wirkung áuf die Muskelarbeit des Menschen auszuüben vermag, die jedoch hinter die günstige Wirkung eines Nahrungsstoffes von gleichem Kalorienwert zurücktritt. Ist jedoch durch sonstige Nahrung für die Zufuhr genügender Spannkräfte gesorgt, so hat die Zufuhr von Alkohol nur mehr schädigende Wirkung, es tritt dann eine Abnahme der Leistungsfähigkeit ein. S ch n y der arbeitete mit Dosen von Bordeauxwein, die $14,7 \mathrm{~g}$ Alkohol entsprachen.

Endlich hätten wir noch eine Ansicht von Zuntz und seinen Mitarbeitern zu erwäbnen, die die Beobachtung von Tissié an einem

1) Siehe die betreffenden Literaturnachweise in den ausführlich hier zitierten Arbeiten.

2) Pflüger's Arch. Bd. 93 S. 451.

3) Höhenklima und Bergwanderungen S. 374. Zuntz, Löwy-Müller und Caspari. 
Rennfahrer betrifft, der nach Alkoholdosen zuerst eine Zunahme der Leistungsfähigkeit und dann eine folgende Herabsetzung derselben zeigte, sowie auf die Anführung Caspari's über die beiden Distanzgeher vom Wettmarsch Dresden-Berlin zu verweisen, von denen derjenige unterlag, der unterwegs Allohol - eine Flasche Wein mit Wasser zu sich genommen hatte. Caspari lässt es dahingestellt sein, ob dies die Ursache der Minderleistung des sonst hervorragenden Sportsmannes war, der früher bereits eine "Weltmeisterschaft" erreicht batte.

Ein Rückblick über diese Ausführungen ergibt wohl ein recht eindeutiges, aber auch ein recht eng begrenztes Bild über unsere wissenschaftlich festgelegten Kenntnisse in bezug auf die Wirkung des Alkohols auf den Kraft- und den Stoffumsatz wie auf die Muskelleistung. Wir wissen sicher, dass Alkohol als Nahrungsmittel unter gewöhnlichen Verhältnissen nicht in Betracht kommt, da er zwar isodyname Mengen an Nahrungsstoffen vertreten kann, seine Menge aber, die ohne Schädigung eingenommen werden kann, eine so geringe ist, dass sie im Verhältnis zum Tagesbedarf verschwindend ist, nebenbei aber auch noch Mehrausgaben durch einen Überschuss an Bewegungen und eventuell auch einen Abbau von Körpereiweiss bedingt, wodurch die geringe, für den Körper durch Alkohol zuführbare Euergiemenge in ihrem Nutzeffekt noch sehr stark beeinträchtigt wird. Hinsichtlich der Muskelarbeit steht fest, dass grosse Alkoholdosen eine Verminderung der LLeistungsfähigkeit neben einer Vermehrung des Stoffumsatzes gegenüber derselben Arbeit ohne Alkoholzufuhr am Hund auslösen, sowie dass durch die Kontraktion einzelner Muskeln oder Muskelgruppen nachgewiesen werden kann, dass bei unermüdeter Muskulatur nach einem anfänglichen, bald vorübergehenden Stadium gestejgerter Leistungsfähigkeit eine Abnahme der Leistungsfähigkeit eintritt, die bis zu $17 \%$ des Normalwertes beträgt. Auf ermüdete Muskulatur wirkt Alkoholzufuhr derart, dass sie auf einige Zeit eine weitere Durchführung der Arbeit ermöglicht, die ohne Alkoholzufuhr nicht oder erst nach einer Ruhepause möglich gewesen wäre. Die die Reizwirkung wie die Leistungsfähigkeit herabsetzende Wirkung des Alkohols ist nach Scheffer auf eine Einwirkung auf nervöse Organe zurückzuführen. Über die Frage, ob Alkohol für die Muskelarbeit verwertet werden kann oder wie sich der Umsatz bei der Einwirkung mässiger Alkoholmengen im Muskel verhält, ferner ob durch die Einwirkung von 
Alkohol eine Änderung im Wirkungsgrad des arbeitenden Muskels eintritt, besitzen wir keine oder nicht hinreichend verwertbare Angaben aus der Literatur.

\section{Marschversuche auf dem Bilkengrat.}

Der Grundzug, nach dem es ermöglicht sein sollte, etwas über die Bedeutung des Alkoholgenusses für die Leistung von Arbeit zu erfahren, wurde oben entwickelt. Der Schwierigkeit der Berechnung halber, nach der es unmöglich ist, aus der Festlegung des respiratorischen Quotienten allein durch Bestimmung des Sauerstoffverbrauchs und der Kohlensäureproduktion zu entscheiden, wie viel an Alkohol, Fett und Kohlehydrat in einem Versuche nebeneinander verbraucht worden sei, und dann im weiteren $\mathrm{zu}$ bestimmen, ob Alkohol als Sparer von Kohlehydrat oder Fett gewirkt habe, sollten die eigentlichen Versuche erst beginnen, wenn man annehmen konnte dass. sämtlicher zugeführter Alkohol bereits verbrannt sei oder nur mehr relativ geringfügige Mengen von Alkohol zur Oxydation gelangen. Darum sollte die erste Zeit nach dem Genuss des Alkohols aus den Beobachtungen ganz ausgeschaltet werden, um sie später einer gesonderten Untersuchung zu unterziehen. Effekt und Wirkungsgrad im Versuch nach Alkoholgenuss sollten im Vergleich zum "Normalversuch", dem zugehörigen Parallelversuch ohne vorherigen Alkoholgenuss, entscheiden, ob dürch den Alkohol eine Änderung der Leistung oder eine Änderung in der Ausnützung der Nahrung als Nachwirkung zustandegekommen sei.

Vorerst musste das Bestreben walten, den Körper in einem guten, gleichmässigen Zustand der Übung für den Steigungsmarsch im Gebirge zu erhalten, so dass in den Kontrollversuchen ebenso wie in den Alkoholversuchen keine unbekannte oder unerwartete Änderung in Verbrauch und Arbeitsleistung, die auf Grund geänderter Übung zu setzen ist, mehr zu gewärtigen war. Die Versuchsstrecke, auf der die Märsche durchgeführt wurden, sowie der Erfolg und der Zeitpunkt, in dem die sich einstellende Übung ihren Höhepunkt erreicht hatte, und die Zahlen für Effekt und Wirkungsgrad im Normalversuch sind in der voranstehenden II. Mitteilung ausführlich erörtert worden. Die Durchführung der Ver'suche war genau dieselbe, wie dort beschrieben ist.

Notwendig muss es erscheinen, einige Bemerkungen über die Versuchsperson zu machen, um deren Verhalten einer Zufuhr von 
Alkohol gegenüber im Alltagsleben beurteilen zu können und ein Verhältnis zwischen dem für sie usuellen Alkoholgenuss und der Zufuhr von Alkohol für die Versuchszwecke festzulegen; dabei soll nochmals erwähnt werden, dass die Absicht, die Versuche an einem Potator durchzuführen und dem gegenüber auch an einem Abstinenten Beobachtungen zu machen, nicht zur Ausführung gelangen konnte und auf einen folgenden Sommer verschoben werden mussten. Einerseits hatte sich der Abstinent, der sich in liebenswürdiger Weise zu den Versuchen bereit erklärt hatte, bereits für die Normalversuche als unbrauchbar erwiesen, und anderseits war infolge der dadurch verlorenen Zeit, wie der Witterungsverhältnisse auch die Ausführung der Beobachtungen am Potator nicht mehr möglich, es blieben also Lücken, die ich aber bald auszufüllen hoffe.

A. D., die Versuchsperson, führte im ganzen 12 Aufstiege auf den Bilkengrat $(2430 \mathrm{~m})$ durch, in deren jeden 4 Versuchsreiben fielen, so dass 48 Marschversuche vorliegen. Von diesen sind 4 Reihen mit 16 Marschversuchen als Alkoholversuche durchgeführt. Weder im Alkohol- noch im Normalversuche wurde jemals irgendein Gefühl von Ermüdung empfunden, Die.Belastung betrug ebenso wie in den Normalversuchen $18-19 \mathrm{~kg}$. Als Marschtempo wurde, wie in Mitteilung II, das für A. D. eben bequemste gewählt, das allerdings dem des durchschnittlichen Touristen gegenüber etwas rascher ist, als es dem Mittel entspricht.

A. D. ist in bezug auf den Alkohol weder Abstinent noch reichlicher Trinker. Bis vor wenigen Jahren trank er der Gewohnheit seiner Heimat gemäss von seinem 14. Lebensjahre an für gewöhnliche Verhältnisse relativ viel Wein, so dass auf den Tag ${ }^{3 / 4}-1$ Liter des allerdings nicht sehr starken Tiroler Tischweins entfallen. In den letzten Jahren trank A. D. fast täglich 1-2 Glas Bier, ausnahmsweise an dessen Stelle auch Wein, in den bei Gesellschaften üblichen Mengen. Vor Beginn der Versuche wurde von ihm wieder mehr Rotwein, und zwar täglich $1 / 2$ Liter etwas stärkeren Dalmatinerweins, getrunken. Auf der Sporner Alpe gelangte, je nach der Zugänglichkeit und dem vorhandenen Vorrat, das, was zur Verfügung stand, an Getränken zum Konsum, wobei an manchen Tagen auch gar kein Alkohol genossen wurde; die Mengen waren aber immer mässige und wohl stets etwas geringere als in der Zeit vor dem Versuchsbeginn.

Für die Versuchsperson können daher Alkoholdosen von $30 \mathrm{ccm}$ und in einem Versuch $40 \mathrm{ccm}$, wie sie in den Versuchsreihen ver- 
wendet wurden, als ganz gewohnte bezeichnet werden, die bei ihm jedenfalls nicht zu Erscheinungen Anlass geben konnten, wie sie im Gefolge der Zufuhr von Alkohol bei den gegen Alkoholgaben nicht abgestumpften Individuen auftreten. A. D. ist übrigens auch gegen etwas grössere Alkoholgaben noch recht unempfindlich. Demuach löste die von ihm in den Versuchen genossene Menge von 30 oder einmal auch $40 \mathrm{ccm}$ Alkohol fast gar keine subjektiven Empfindungen aus und erzeugte nicht das mindeste Gefühl von Eingenommenheit oder von Unlust zum Gehen. Die einzige Wahrnehmung, welche zu machen war, bestand in einer Empfindung von Schwüle und Dunstigkeit, wie man sie im Hochgebirge sonst vor Wetterunschlägen zu haben pflegt, wenn man aus dem Obdach am frühen Morgen ins Freie tritt und anstatt der erfrischenden Kälte des grauenden Tages schwüle, warme Luft einatmet. Auch nach mehr als einer Stunde nach dem Alkoholgenuss war dieses Gefühl nicht gewichen; beim Marsch auf stark ansteigendem Terrain kam noch die Empfindung, etwas schwerer zu atmen hinzu.

Zum Genuss wurde auschliesslich reiner, rektifizierter $98 \%$ iger Alkohol verwendet, mit $125-250 \mathrm{ccm}$ Wasser vermischt, der Geschmack war mit Zucker aufgebessert, der von der sonst üblichen Frühstücksration im Tee abgezogen wurde, so dass die Alkoholgabe also keinen. Ersatz, sondern eine Zulage zu dem sonst genommenen Morgenimbiss bedentete, ohne dass noch ein weiterer Zuckerzuschuss erfolgt wäre, dagegen wurde die sonst genossene Brotration um etwa $1 / 3$ vermehrt, so dass im ganzen eine Menge von entrindetem Weissbrot genossen wurde, die etwa einer gewöhnlichen Semmel entspricht.

Der Grund, warum ausschliesslich Alkohol und nicht eines der üblichen geistigen Getränke verwendet wurde, liegt darin, weil es zweckmässiger schien, für die Grundversuche vorerst die Nebenwirkungen, die durch Ester und Bouquetstoffe erzeugt werden, ganz auszuschalten und die Entscheidung über deren Wirksamkeit sowie über jene der Form und Konzentration, in der der Alkohol genossen wird, je nach den Ergebnissen dieser Versuche späteren Studien zugrunde zu legen.

Ob die Einfuhrung von Alkohol am Morgen neben etwas Brot, so dass dieser absichtlich nicht auf nüchternen Magen genommen wurde, zugleich mit einer Tasse schwachen Tees und Zucker für die Versuchsperson nicht besondere, ungewohnte Bedingungen schaffte, ist 
nicht von der Hand zu weisen, wenn auch ein besonderer Einfluss der Einfuhr am Morgen höchst unwahrscheinlich ist. A. D ist zwar nicht gewöhnt, am Morgen oder im Laufe des Tages alkoholische Getränke zu sich zu nehmen, wenn in den Versuchen aber doch am Morgen eine Zufubr von $30 \mathrm{ccm}$ Alkohol erfolgte, so geschah dies zugleich unter Einnahme von etwas Tee und Brot wie Zucker, so dass die Verbältnisse durchaus keine so abnormen mehr waren, wie überhaupt nach den Versuchen von Schnyder eine Abschwächung der möglichen günstigen Wirkung des Alkohols dadurch nicht zu erwarten war. Die Tatsache, dass A. D keine narkotische Wirkung oder keine subjektive Empfindung einer Leistungsfähigkeitsherabsetzung wahrnahm, sprechen ebenfalls dafür, dass diese Form der Zuführung für die Versuchsperson eine tatsächlich geeignete und einwandsfreie war, um so mehr als gegenüber der Einschaltung unkontrollierbarer Ausgaben für Verdauungsarbeit durch gleichzeitige Zufuhr von mehr Nahrung neben dem Frühstück oder durch die Verlegung der Versuche auf eine andere Tageszeit der Mindereinnahme von Speise entschieden der Vorzug gegeben werden musste.

Die Versuche selbst trat ich in vollkommener Gleichgültigkeit gegen die Resultate, die sich etwa ergeben sollten, an, so dass mir jede Voreingenommenheit fehlte, hatte doch überhaupt nur ein $\mathrm{Zu}$ fall dazu Anlass gegeben, mich mit der Alkoholfrage zu beschäftigen, die mir vorher vollständig ferne gelegen war. Ich besass zwar eigene Erfahrungen im Gebirge, nach denen ich den Genuss von Alkohol, den ich in meiner Jugend auf Touren noch gewöhnt war, ganz aufgegeben hatte, so dass ich später nie mehr alkoholische Getränke mit mir führte, dagegen trinke ich auch jetzt noch an Rasttagen wie auf Schutzhütten nach vollbrachter Marschleistung geringe Mengen von Alkohol als Genussmittel gerade so, wie ich es im täglichen Leben zu tun pflege. Ausserdem war mir bis zur Zusammenstellung dieser Versuche der grössere Teil der einschlägigen Literatur, da ich mich mit der Frage nicht beschäftigt hatte, nur aus Referaten und flüchtiger Lektüre geläufig und fehlte mir auch jeder Überblick und jedes begründete kritische Urteil über die bisher vorliegenden Versuchsresultate, so dass mir das Resultat der durchzuführenden Versuche ganz unklar war und, wie sich schliesslich bei der Berechnung in übersichtlichen Zusammenstellung der Versuche ergab, ein ganz anderes wurde, als ich mir anfänglich nach dem Ausfall der Analysen und der Ausmessung der Wege gedacht hatte. 
Sollten die Versuche eine Herabminderung der Marschleistung durch Alkoholgenuss ergeben, oder sollte es sich herausstellen, dass diese vorhanden, aber mit keinem Mehrverbrauch verbunden ist als dies der Norm entsprechen würde, oder sollte die Empfindung erschwerten Atmens eine rein subjektive oder durch die Förderung grösserer Luftvolumina bedingte sein, ebenso wie sich die Empfindung, dass man um so leichter geht, je höher man im Gebirge aufsteigt, als Täuschung herausgestellt hatte, auf alle Fälle musste ein Resultat sich ergeben, das neue Aufschlüsse in der Frage gab, sollten diese nun nach der einen oder anderen Richtung hin ausfallen.

Auf die Anführung dieser Verhältnisse lege ich darum Gewicht, weil die Annahme einer Autosuggestion bei Alkoholversuchen immer sehr naheliegend ist, da sich die Kenntnis der Tatsache, dass Alkohol eingenommen wurde, für die Versuchsperson nicht umgehen lässt; dass für mich derartige Bedenken auszuschliessen sind, ist nach dem erwähnten festgelegt; zudem muss aber noch hervorgehoben werden, dass die Versuchsmethodik selbst eine Fälschung der Resultate durch Autosuggestion fast unbedingt ausschliesst. Kann immerhin ein Individuum unter der suggerierten Empfindung; weniger marschleistungsfähig zu sein, mit geringerer Schnelligkeit gehen oder eventuell am Ergographen eine kleinere Arbeit leisten, so wird sie doch dies Kunststück auf keinen Fall fertig bringen, auch wenn sie die Atmung willkürlich verändert, die Kohlensäureproduktion und den Sauerstoffverbrauch auf längere Zeit hin merklich und konstant $\mathrm{zu}$ ändern, wenn zugleich eine beträchtliche Arbeit geleistet wird; ganz ausgeschlossen ist es jedoch, dass eine solche wesentliche Änderung sich in gleicher Grösse auf Stunden erstreckt, auch wenn man für diese ganze Zeit eine Mehrausgabe durch willkürlich geänderte Atemarbeit, wie dies Bornstein in seinen kurzdauernden Versuchen anstrebte, annehmen wollte.

Bevor wir auf die eigentlichen Versucbsergebnisse eingehen, ist es noch wichtig einen Einblick dahin zu gewinnen, ob man eine Veränderung der Atmung durch den Alkohol erwarten dürfe, und über welche Zeit hinaus man sich noch ein Zustandekommen von Verbrennung des zugeführten Alkohols vorzustellen hat.

Die bekannten Tatsachen über den Einfluss des Alkohols auf Mechanik und Chemismus der Atmung hat Jaquet ${ }^{1}$ ) in den Er-

1) Ergebnisse der Physiologie Bd. 2 erste Hälfte S. 567. 1903. 
gebnissen zusammengestellt, so dass auf die Ausführungen dieses Autors verwiesen werden kann, aus denen hervorgeht, „dass kleine Alkoholdosen ohne Wirkung auf den respiratorischen Stoffwechsel sind", und dass bei dem einigermassen an Alkohol gewöbnten Mensehen weder eine Veränderung des Atmungsmechanismus, noch eine Änderung der Kohlensäureproduktion und des Sauerstoffverbrauchs durch Alkoholgenuss ausgelöst wird.

Über die Raschbeit, mit der der Alkohol verbrannt wird, konnte ich vollkommen befriedigende Angaben nicht finden, so dass ich selbst die Entscheidung dieser Frage in Angriff nehmen wollte, woran mich aber eine Reihe anderer Arbeiten bisher hinderten, weshalb ich diesbezüglich auch auf Versuche, die ich bald fertiggestellt zu haben hoffe, verweisen muss. Aus den Angaben von Hellsten entnehmen wir nur, dass nach etwa 2 Stunden die Nachwirkung des eingeführten Alkohols bei Dosen von $80 \mathrm{~g}$ zu verschwinden begann, wie wir ferner aus der Arbeit von Strassmann ${ }^{1}$ ) ersehen, dass bei der Annahme einer Ausscheidung von 5-10\% Alkohol, die nach den neuesten Ergebnissen von Atwater etwas zu hoch gegriffen ist und nur etwa $2 \%{ }^{2}$ ) betragen dürfte, bis zur dritten Stunde die Hauptmenge des Alkohols verbrannt sein dürfte und zwar dies um so mehr, als bei der Leistung von Arbeit die Abventilation als grösser und auch die Verbrennung als rascher vor sich gehend angenommen werden muss. Bezüglich der Versuche Strassmann's müssen wir nur noch erwähnen, dass diese nach einer Zufuhr von 50-60 $\mathrm{g}$ Alkohol durchgeführt sind, so dass die Annahme, die Hauptmenge des Alkohols sei in unseren vorliegenden Marschversuchen bereits nach etwa zwei Stunden verbrannt, gerechtfertigt erschier. Das rasche Einsetzen der Alkoholwirkung und dann das beobachtete Abklingen derselben bei den Ergographen-Versuchen liessen die Deutung ebenfalls begründet erscheinen.

Trotz dieser vorliegenden, wie erwähnt, noch zu ergänzenden Versuchsergebnisse müssen wir uns fragen, wie das Auftreten von Alkoholdampf die Analysen und damit die Berechnung des Umsatzes hätte beeinflussen können, wenn zur Zeit der Marschversuche noch Alkohol resorbiert und verbrannt worden wäre. Sollte auch eine Verbrennung und Ausscheidung von Alkohol in die Versuchsperiode

1) Pflüger's Arch. Bd. 49 S. 314.

2) l. c., Atwater und Benedict S. 258. 
fallen, wie tatsächlich aus den später zu beschreibenden Versuchen hervorgeht, so musste also die von A twater gemessene Gesamtausscheidung von $2 \%$ im ungünstigsten Falle eben bis an das Ende der Versuchsdauer, der Aufwärtsmärsche reichen, so dass sich für $2 \%$ von $40 \mathrm{ccm}$ der maximal eingeführten Menge, schlechtweg $0,6 \mathrm{~g}$ Alkohol im Verlauf von vier Stunden durch die Exspirationsluft bätten entfernen müssen, was pro Minute einer Abgabe von $0,0025 \mathrm{~g}$ Alkohol entspricht; bei einem durchschnittlich pro Minute geatmeten Volum von 50 Litern entfallen daher auf die Gasprobe von $300 \mathrm{ccm} \frac{300 \cdot 0,0025}{50000}=0,000016 \mathrm{~g}$ Alkohol, die als Dampf das Volum von $0,008 \mathrm{ccm}$ einnehmen würden, so dass die Absorption des eventuell ausgehauchten Alkoholdampfes im Kondenswasser und Wasser der Proberöhre in keinem Fall eine Grösse erreicht, die auch nur im entferntesten eine Rückwirkung auf die Volumbestimmung, geschweige denn auf die Menge von Kohlensäure, die wir analytisch bestimmen könnten, haben könnte, da auf diese nur $1 / 25$ bezw. $1 / 7$ dieses auf $100 \mathrm{ccm}$ Gas bezogenen Wertes wirken könnte.

Nun wäre noch die zweite Frage zu erledigen, wie die Verbrennung von Alkohol während des Marsches in der Versuchsstrecle bei der Bestimmung des Umsatzes an Kalorien sich der Berechnung hindernd in den Weg stellen kann und welche Fehler wir dabei begehen.

Wird der Alkohol in der Periode des Anmảrsehes nicht vollständig verbrannt, so müssen während des Marsches die respiratorischen Quotienten niedriger werden. Bei ausschliesslicher Verbrennung: von Alkohol müssten sie den Wert von 0,667 erreichen, wenn aber Fett, Kohlehydrat und Alkohol verbrannt werden, je nach der Beteiligung der einzelnen Stoffe zwischen 1 und 0,667 liegen.

Für Quotienten unter 0,707, dem respiratorischen Quotienten bei Fettverbrennung, wäre die Rechnung daher einfach. Für respiratorische Quotienten über 0,707 können wir jedoch die Mengen an Fett, Alkohol und Kohlehydrat, die zur Verbrennung gelangten, nur dann bestimmen, wenn wir über genaue Grundlagen bezüglich der zugeführten Nahrung und über den Gesamtstoffwechsel verfügen, dann ist allerdings eine Berechnung annähernd möglich. Da uns derartige Grundlagen in den vorliegenden Versuchen fehlen, weil ein Stoffwechselversuch mit den Respirationsversuchen mit Absicht nicht verbunden wurde, können wir eine derartige Berechnung auch nicht 
versuchen, worin wir aber kaum einen Nachteil erblicken können, da bei der Veränderlichkeit des respiratorischen Quotienten durch geringfügige äussere Anlässe die Fehlergrenzen einer derartigen Rechnung nicht geringere sind, als wenn wir den unten gewählten einfacheren Weg einschlagen und mit Absicht einen nach ganz bestimmter Richtung hin wirkenden und in seinem Maximalausmass gekannten Fehler begehen.

Durch die Verbrennung von Kohlehydrat wird der respiratorische Quotient steigen, durch die Verbrennung von Alkohol und Fett wird er sinken müssen. Nun rechnen wir in den folgenden Versuchen so, als ob unsere ursprüngliche Voraussetzung richtig wäre, dass während der Marschversuche nicht mehr nennenswerte Mengen von Alkohol verbrannt seien, also als wäre wie sonst nur Fett und Kohlehydrat verbrannt worden und kein Alkohol zur Oxydation gelangt. Es entspricht nach den Ausführungen von Zuntz ${ }^{1}$ ) ein Absinken des respiratorischen Quotienten um 0,001 zwischen den Quotienten der Fettrerbrennung 0,707 und jenen der Kohlehydratverbrennung 1,00 für jeden Liter verbrauchten Sauerstoffes eine Minderproduktion von 0,00123 Kalorien gegenüber der Verbrennung von Kohlehydrat allein. Da der Alkohol bei seiner Verbrennung 7,07 Kalorien pro Gramm liefert, so müssen bei seiner Verbrennung auf den Verbrauch von 1 Liter Sauerstoff 4,843 Kalorien entstehen ${ }^{2}$ ), während bei der Verbrennung von Fett dem Verbrauch von 1 Liter Sauerstoff eine Produktion von 4,686 Kalorien entspricht. Wir hätten daher beim Absinken des Quotienten von 0,707 auf 0,667 für jede Abnahme des Quotienten um 0,001 eine Zunahme der Verbrennungswärme, die jedem Liter Sauerstoff entspricht, von 0,0039 gegenüber der Verbrennung von Fett anzusetzen.

Wäre, was dem allerursprünglichsten Falle entspricht, ausschliesslich Kohlehydrat und Alkohol verbrannt, so ist die Differenz der Brennwerte, die dem Verbrauch von einem Liter Sauerstoff entsprechen, 5,047-4,843 Kalorien bei einem Absinken des Quotienten von 1,00 auf 0,667 , also für die ganze Abnahme des Quotienten um 0,333, eine Verminderung des Brennwertes, die dem Verbrauch eines Liters Alkohol entspricht, um 0,204, so dass wir für eine Änderung des Quotienten

1) Pflüger's Arcb. Bd. 68 S. 201.

2) Siehe auch Höhenklima und Bergwanderungen usw. S. 97. 
um 0,001 in diesem Falle eine Verminderung der Brennwärme für einen Liter Sauerstoff um 0,00061 Cal. anzusetzen haben. Es ergibt sich also, dass wir für jeden Liter Sauerstoff unter der Annahme von Fettverbrennung gegenüber dem für Alkoholverbrennung verbrauchten Sauerstoff ein Zuwenig von $0,00123-0,00061=$ 0,00062 Cal. eingesetzt hätten, so dass auf die im Durchschnitt pro Minute für die Arbeit verbrauchte Sauerstoffmenge von 2 Litern, in diesem extremen Falle also bei ausschliesslicher Verbrennung von Alkohol und Kohlehydrat und bei einem Absinken des Quotienten um 0,20 im Mittel ein zu geringer Wärmewert von $2 \times 200 \times 0,62$ cal. $=248$ cal. in Ansatz gebracht worden wäre. Dem gegenüber steht die bestimmte Gesamt-Verbrennungswärme für Arbeit von rund 9000 cal. per Minute; infolge der weiteren Verkleinerung dieses möglichen Fehlers durch die Division durch die Leistung von Arbeit in Meterkilogrammen, die auf $800 \mathrm{mkg}$ per Minute sich ergab, wird der berechnete Wirkungsgrad selbst in diesem äussersten Falle nicht nennenswert beeinflusst so dass ein wesentlicher Fehler durch die Unmöglichkeit, die im Zeitteilehen jeweilig verbrannte Alkoholmenge berechnen zu können, sich für die Ergebnisse nicht ableitet (s. S. 394).

Wir wollen uns dessenungeachtet gegenwärtig halten, dass die gefundenen Wärmewerte, welche sich aus unserer Rechnung ergaben, als Minimalwerte anzusehen sind, dass der Umsatz an Kalorien für den Fall in den Versuchen noch nicht aller Alkohol verbrannt war und solcher weiter zur Oxydation gelangte, etwas zu niedrig gegriffen ist, wir also zugunsten einer Wirkung des Alkohols gerechnet haben, indem wir die Ausgaben des Körpers höehstens um 2,8\% geringer einsetzten, als sie in diesem Falle sein mussten. Ist der Korrekturwert, der sich aus unseren Betrachtungen für die Berücksichtigung einer weiterbestehenden Alkoholverbrennung ergeben müsste, selbst wenn wir annehmen, es sei nur Kohlehydrat und Alkohol verbrannt worden, in den Endresultaten zu vernachlässigen, so wollen wir doch auch ferner festhalten, dass dadurch der Wirkungsgrad sich nur als ein günstigerer hat ergeben müssen, wir also auch eher im Sinne einer besseren Ausnutzung der Brennstoffe des Körpers bei Alkoholnahrung gerechnet hätten.

Bezüglich der Methodik ist nun noch eines nachzutragen. Wenn W ol f e r s nachgewiesen hat, dass durch Alkoholzufuhr beim Kaninchen ein Steigen des Sauerstoffverbrauchs eintritt, so kann diese Tatsache nicht obne weiteres auf den Menschen, der Alkoholdosen gewöhnt 
ist, übertragen werden, wir müssen uns hier vielmehr den von Geppert am Menschen festgestellten Tatsachen anschliessen, dass eine solche Änderung jedenfalls innerhalb mässiger Dosen nicht zu erwarten ist. Alle Versuche, um die es sich hier handelt, betreffen aber nur die allererste Zeit.nach der Alkoholzufuhr; während die für unsere Versuche hauptsächlich in Betracht kommende Nachperiode nicht in den Kreis der Beobachtungen einbezogen ist. So weit man aus den Untersuchungen von $A$ twater und Benedict Schlüsse ziehen kann, ist tatsächlich auch für wesentlich nach der Zufuhr von Alkohol gelegene Zeitpunkte eine Änderung des Gaswechsels nicht zu erwarten. Aus diesen Gründen mag es verzeiblich erscheinen, wenn wir unter der böchst wahrscheinlichen Annahme, es seien bei dem Fehlen von Änderungen des Stoffwechsels in der eigentlichen Alkoholperiode auch in der.späteren Zeit keine Einflüsse der Alkoholzufuhr auf den Ruhegaswechsel mehr zu erwarten, Ruheversuche mit denselben Alkoholdosen, wie die für die Marschversuche angewendeten waren, nicht durchführten, da die Zeit dies nicht gestattete.

Auch auf Horizontalmarschversuche unter dem Einfluss des Alkohols zum Vergleiche mit den Horizontalmärschen ohne Alkoholzufuhr musste verzichtet werden, da die Ungunst der Witterung sie nicht zuliess und es wünschenswerter ersehien, die Tage mit gutem Wetter auf die Versuche mit Steigarbeit zu verwenden, bei denen das, was in den Horizontalmärschen zum Ausdruck gekommen wäre, sich nur noch eklatanter ergeben musste. Wir müssen dabei der Aufgabe gerecht werden, festzustellen, ob die Subtraktion einer zu niederen Horizontalkomponente die Resultate hätte wesentlich beeinflussen können.

Wie in der ersten Mitteilung erwähnt, ist die auf der Sporner Alpe für mich gewonnene Horizontalkomponente überhaupt sehr hoch bemessen. Nehmen wir nun an, es wäre durch die Zufuhr von Alkohol - ein Minderverbrauch nach Alkoholzufuhr wird wohl vom eifrigsten Verfechter des Alkoholgenusses nicht angenommen werden - ein Mehrverbrauch für die Fortbewegung von $1 \mathrm{~kg}$ über $1 \mathrm{~m}$ Weg zustande gekommen, der den Normalverbrauch bei derselben Geschwindigkeit um 10\% übersteigt, so wird der für die Korrektur $\mathrm{zu}$ berechnende Wert, da in meinen Versuchen der Verbrauch für die Steigarbeit das Zehnfache des Verbrauchs für die Fortbewegung auf gleich langer ebener Strecke beträgt, einem Hundertstel dieses 
Wertes entsprechen. Nachdem nun die Steigarbeit im Durchschnitt etwa $800 \mathrm{mkg}$ pro Minute betrug, kann für die Berechnung des Verbrauchs pro Meterkilogramm nur mehr 1/80000 des Wertes der für die Steigarbeit verausgabten Kalorien in dem Endresultat zum Ausdruck kommen. Nun berücksichtigen wir beim Vergleich des Umsatzes für das Meterkilogramm Arbeit überhaupt nur die ersten beiden Stellen, so dass der Korrekturwert immer noch weit unter die Grenze jener Grössen fällt, die für uns in Betracht kommen. Da wir bei der Berechnung des Effekts aber ausserdem für die Kalorien der Horizontalkomponente denselben Wirkungsograd wie für die Kalorien, die für Steigarbeit aufgewendet wurden, annehmen, so tragen wir bei der Feststellung des Gesamteffektes auch einer gleichartigen Änderung des Verbrauchs für die Horizontalbewegung Rechnung, wie wir diese für die Steigarbeit ermittelten.

Die Versuche begannen mit der Zubereitung des Frühstücks noch vor Tagesanbruch. Es folgte das Verzehren des Frühstücks, das Ausmessen der $30 \mathrm{ccm}$ Alkohol mit der Pipette, die mit Wasser und Zucker versetzt, sofort getrunken wurden; dann wurden noch einige Bissen Brot gegessen, die Notierungen der Schemen für die Versuchsprotokolle, die wir während des Marsches benötigten, vorgenommen, Körpergewicht, Barometerstand und Temperatur festgestellt und nach einigen Verrichtungen, die der Haushalt erforderte (wir lebten ohne Bedienung), aufgepackt und beim Tagesgrauen der Anmarsch zum Tramosner Tobel ${ }^{1}$ ) angetreten, so dass bis zum Aufbruch vom Genuss des Alkohols $1 / 4-1 / 2$ Stunde verstrich. Der Anmarsch nahm mehr Zeit als in den Normalversuchen, im Mittel eine Stunde, in Anspruch; trotz der gleichen Übung hatten wir in den Alkoholversuchen eine 10-15 Minuten längere Gebzeit hierfür nötig als im Normalversuch, wurden also gewissermassen auf eine Stufe geringerer Übung zurückgeschlagen, bei der wir auch im Normalversuch für den Anmarscì eine Stunde benötigt hatten.

Ohne Rast schloss sich direkt der "Spülmarsch", der "Vormarsch" und der eigentliche Versuchsmarsch in der ersten Versuchsstrecke an. Bezŭglich der Beschaffenheit und Lage der Versuchsstrecken sei nochmals auf die zweite Mitteilung verwiesen. Die Alkoholversuche schieben sich immer derart zwischen die Normalversuche ein, dass jedem der Alkoholversuche immer ein Normal-

1) Siehe das Kärtchen. II. Mitt. S. 221. 
versuch zugehört, so ist der Kontrollversuch zu Nr. $33 \mathrm{Nr} .32$ auf Generaltabelle II S. 258 der vorigen Mitteilung. $\mathrm{Zu} \mathrm{Nr.} 35$ gehört Nr. 34, ebenso sind Nr. 37 und Nr. 38 und 40 zusammengehörige Versuchsreihen.

$\mathrm{T}$ a -

Übersicht iber den Energieumsatz bei Marsch-

\begin{tabular}{|c|c|c|c|c|c|c|c|c|c|c|c|c|c|}
\hline \multirow{3}{*}{ Nr. } & \multirow{3}{*}{ Tag } & \multirow{3}{*}{ 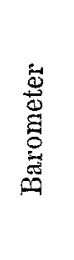 } & \multirow{3}{*}{ 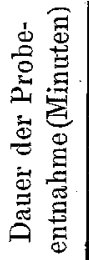 } & \multicolumn{2}{|c|}{$\begin{array}{l}\text { Atemgrösse } \\
\text { Liter }\end{array}$} & \multirow{2}{*}{\multicolumn{2}{|c|}{$\begin{array}{c}\text { Zusammen- } \\
\text { setzung } \\
\text { der } \\
\text { Exspirations- } \\
\text { luft } \\
\end{array}$}} & \multicolumn{2}{|c|}{$\begin{array}{l}\text { per Minute } \\
\text { ccm }\end{array}$} & \multirow{3}{*}{ 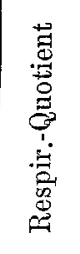 } & \multicolumn{3}{|c|}{$\begin{array}{c}\text { Nach Abzug } \\
\text { des Ruheverbranchs }\end{array}$} \\
\hline & & & & \multirow{2}{*}{ 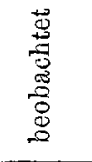 } & \multirow{2}{*}{ 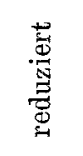 } & & & \multirow{2}{*}{ 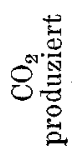 } & \multirow{2}{*}{$0^{\infty}$} & & \multirow{2}{*}{ 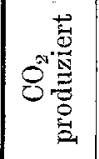 } & \multirow{2}{*}{ 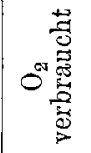 } & \multirow[b]{2}{*}{$\begin{array}{l}\dot{q} \\
1 \\
\dot{\mu}\end{array}$} \\
\hline & & & & & & $\begin{array}{l}\frac{8}{8} \\
8 \\
8\end{array}$ & 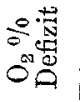 & & & & & & \\
\hline \multirow{4}{*}{$\begin{array}{r}33 a \\
b \\
c \\
d\end{array}$} & 6. Sep & 1,8 & & & & 4,95 & 5,91 & 1666,8 & 2214,6 & 0,753 & 1478,7 & 1974,3 & 0,7 \\
\hline & & & & & & 4,63 & & & & 0,778 & & & \\
\hline & "z & 578 & 3,750 & 51, & 6, & 4.60 & 5,98 & 1685,4 & 217 & 0,776 & 1497,3 & 1931,1 & 0,7 \\
\hline & & 568 & 4,000 & 54 & 8, & 4,92 & 6,06 & 1872,0 & 2306,8 & 0,811 & 1683,9 & & 0,8 \\
\hline \multirow{4}{*}{$\begin{array}{r}35 \mathrm{a} \\
\mathrm{b} \\
\mathrm{c} \\
\mathrm{d}\end{array}$} & 11. Sept. & 611,3 & 4,167 & 56,84 & 42,44 & 4,45 & 5,42 & 1888,8 & 2298,8 & 0,822 & 1700,7 & 2058,4 & 0,823 \\
\hline & $"$ & 594 & & & & & & & & & & & 0,841 \\
\hline & $"$ & & 3,855 & & & & 5,39 & & & & & & 0,8 \\
\hline & $\%$ & 0 & 4,033 & & & 4,9 & 5,72 & & & 0,864 & & & \\
\hline \multirow{4}{*}{$\begin{array}{r}36 \mathrm{a} \\
\mathrm{b} \\
\mathrm{c} \\
\mathrm{d}\end{array}$} & 12. Sept. & 611,2 & 4,383 & 52,05 & 38,86 & 4,66 & 5,51 & 18 & & 0,8 & & & \\
\hline & & & & & & & & & & & & & \\
\hline & " & & 3,924 & & & 4.5 & & & & & & & \\
\hline & $n$ & 565,7 & 4,250 & & & 4,6 & 5,77 & & & 0,8 & & 1922,3 & 0,809 \\
\hline \multirow{4}{*}{$\begin{array}{r}40 \mathrm{a} \\
\mathrm{b} \\
\mathrm{c} \\
\mathrm{d}\end{array}$} & 18. Sept. & 611 & 4,4 & & & 4,54 & 5,67 & & & & & & \\
\hline & & & & & & & & & & & & & \\
\hline & 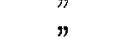 & & 3,9 & & & 4,62 & 5,7 & & & 0,7 & & & 0,80 \\
\hline & & 567,9 & 4,483 & & & 4,70 & 5,90 & 1642,0 & & 0,7 & & 1823,0 & 0,79 \\
\hline
\end{tabular}

Der oberflächliche Vergleich dieser Tabelle mit der Generaltabelle II der vorigen Mitteilung, die die Versuche enthält, die im selben Zustand der Übung durchgeführt wurden, gibt auf den ersten Blick vielleicht nur das eine Resultat zu erkennen, dass sämtliche Zahlen der beiden letzten Kolumnen der Alkoholtabelle, die den Verbrauch pro Meterkilogramm Steigarbeit in Kalorien, beziehungsweise in Meterkilogrammen ausdrücken, höher sind als in den entsprechenden Spalten der Normalversuchstabelle, ein Verhalten, auf das wir sofort des näberen eingehen werden. Bei genauerem Zusehen finden wir aber fast in allen Spalten durchgreifende Unterschiede ausgeprägt, die wir nur in den ersten Kolumnen nicht zu erkennen vermögen.

Die beobachteten, per Minute geatmeten Volumina und die reduzierten und unreduzierten Minutenvolumina verhalten sich ganz 
ähnlich, wie in den Normalversuchen; sie sind weder grösser als diese noch zeigen die beobachteten Volumina ein Ansteigen, wie wir es in'den ersten Versuchen, bevor sich eine vollkommene Übung ausgebildet batte, meist nachweisen konnten; in Versuch 33 ist ganz

belle I.

versuchen am Bilkengrat nach Alkoholgenuss.

\begin{tabular}{|c|c|c|c|c|c|c|c|c|c|c|c|c|}
\hline \multicolumn{2}{|c|}{ Gesamt- } & \multicolumn{2}{|c|}{ per Minute } & \multirow{3}{*}{ 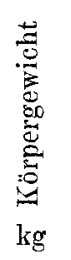 } & \multirow{3}{*}{ 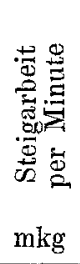 } & \multicolumn{2}{|c|}{$\begin{array}{l}\text { per Meter } \\
\text { Weg und } \\
\mathrm{kg} \text { Gewicht }\end{array}$} & \multicolumn{3}{|c|}{$\begin{array}{l}\text { Calorischer Wert } \\
\text { für die }\end{array}$} & \multirow{2}{*}{\multicolumn{2}{|c|}{$\begin{array}{c}\text { Für } 1 \mathrm{mkg} \\
\text { Arbeit } \\
\text { umgesetzt }\end{array}$}} \\
\hline \multirow{2}{*}{$\sum^{\infty 0}$} & \multirow{2}{*}{ 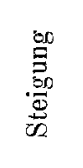 } & \multirow{2}{*}{$\stackrel{\infty}{\infty}$} & \multirow{2}{*}{ 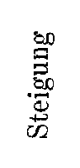 } & & & \multirow{2}{*}{8} & \multirow{2}{*}{ 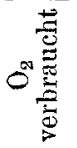 } & \multirow{2}{*}{ 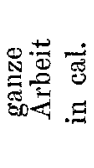 } & \multirow{2}{*}{ 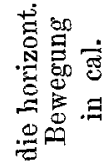 } & \multirow{2}{*}{ 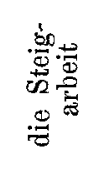 } & & \\
\hline & & & & & & & & & & & ฮี่ & 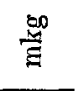 \\
\hline 56,7 & 43,17 & 34,82 & 9,59 & 81,38 & 780,4 & 5221 & 6970 & 9354,8 & 1817,2 & 7537,6 & 9,653 & 4,123 \\
\hline 61,6 & 41,71 & 35,91 & 9,27 & 81,38 & 754,0 & 5140 & 6610 & & & & 9,735 & 4,158 \\
\hline 137 & 37,12 & 36,59 & 10,03 & 81,38 & 815,9 & 5032 & 6490 & & 190 & & 8,945 & 3,821 \\
\hline 162 & 42,07 & 40,60 & 10,52 & 81,38 & 855,4 & 5100 & 6258 & & 211 & 7840,9 & 9,160 & 3,913 \\
\hline 156,1 & 43,17 & 37,61 & 10,36 & 81,02 & 839,3 & 5581 & 6756 & 9938,1 & & 7984,8 & 9,513 & 4,06 \\
\hline & 41, & 37,29 & 9,63 & 81, & 779,8 & 5183 & 6181 & & & & 9,123 & 3,896 \\
\hline 137,5 & 37,63 & 35,56 & 9,75 & 81,0 & 790,0 & 5560 & 6418 & & & & 9,097 & 3,885 \\
\hline 162,4 & 42,07 & 40,29 & 10,43 & 81,02 & 845,0 & 5249 & 6061 & 9579,0 & 2091,4 & 7487,6 & 9,069 & 3,874 \\
\hline 1567 & 43,17 & 35,75 & 9,85 & 82,89 & 816,4 & 5351 & 6417 & 9254,0 & 1856,8 & 7397,2 & 9,062 & 3,876 \\
\hline & 41,71 & 35,92 & 9,27 & 82,89 & 768 & 5003 & 6094 & & & & 8,913 & 3,867 \\
\hline & & 34,96 & 9,59 & 82,89 & 794,6 & 5095 & 6323 & & & & 8,750 & 3,737 \\
\hline 162,5 & 42,0 & 38,21 & 9,90 & 82,89 & 820,5 & 4910 & 6069 & 9250,5 & 2029,7 & 7220,8 & 8,801 & 3,759 \\
\hline 156,7 & & 35,07 & 9,66 & 82,65 & 798,5 & 5491 & 6812 & 9554,6 & & & 9,639 & 4,117 \\
\hline & & & & 82,65 & 738,8 & 5257 & 6161 & & & & & \\
\hline 137, & 37,64 & 35,18 & 9,65 & 82,65 & 797,3 & 5192 & 6385 & 9050,8 & 1864,0 & & 9,015 & 3,850 \\
\hline 162,4 & 42,07 & 36,23 & 9,38 & 82,65 & 775,6 & 5018 & 6089 & 8747,8 & 1919,4 & 6828,4 & 8,864 & 3,760 \\
\hline
\end{tabular}

analog dem Versuch 32 dies Verhalten noch ausgesprochen, anscheinend mit der Gewöhnung bat sich dies verwischt und ist auch in den späteren Alkoholversuchen nicht wieder zum Vorschein gekommen, was wir vermutungsweise als eine zweckentsprechende Ersparnis an Atemarbeit schon in der zweiten Mitteilung gekennzeichnet haben. Trotzder Empfindung, schwerer zu atmen, lässt die Atemmechanik im Alkoholversuch nicht das mindeste nachweisen, was dieses subjektive Gefühl begründen könnte, es wird weder mehr, noch wie die Zahlen der A temzüge ergeben, öfter geatmet; wir finden wie im Normalversuch 25-33 Atemzüge per Minute.

Auch die Zusammensetzung der Exspirationsluft lässt weder in bezug auf ihren Kohlensäuregehalt noch in bezug auf das Sauerstoffdefizit einen auffallenden Untersehied gegen die Norm erkennen, 
dass aber doch ein Unterschied besteht, wird sofort bei Beachtung des respiratorischen Quotienten klar.

Aus den Tabellen X und XI der vorigen Mitteilung leiteten wir $a b$, dass im Beginne der Versuche zur Zeit fehlender Übung im Marsch noch ein mehr oder minder wirres Durcheinanderfallen der respiratorischen Quotienten zustande kommt, dass sich aber doch schon eine Tendenz ganz klar erkennen lässt, die dahin geht, dass die respiratorischen Quotienten das Bestreben haben, vom Beginne des Aufstieges an im Verlaufe der Arbeit weiter abzusinken, ein Verhalten, das in den Versuchen der zweiten Periode ganz deutlich und einhellig ausgesprochen ist, ohne dass eine einzige $\Lambda$ bweichung sich eingestellt hätte.

Die zwischen die Normalversuche mit ihrem gesetzmässigen Abfall der Quotienten eingeschobenen Alkoholversuche, die also ebenfalls in die zweite Periode der Märsche fallen, scheinen bei einem Blick auf die Generaltabelle auch ganz wirr durcheinanderfallende Quotienten zu haben, so dass ich selbst glaubte, es sei dies der Ausdruck einer gewissen Ungeschicklichkeit im Atmen, die sich etwa ebenso wie in den Muskelkurven Hellsten's in den Alkoholreihen ausspricht, indem bald flacher, bald tiefer geatmet wird und dadurch präformierte Kohlensäure mit einigen tiefen Atemzügen ausgeatmet wird und so eine Erhöhung des Quotienten in manchen Versuchen bewirkte, in anderen sie eventuell niederer erscheinen liess. Bei den grossen per Minute ventilierten Gasmengen und bei der Gleichmässigkeit der per Minute geatmeten Volumina ist dies jedoch höchst unwahrscheinlich, um so mehr als ein Zusammenstellen der Quotienten in eine Tabelle uns auf einmal ein ganz anderes Bild erkennen lässt, wenn wir Tabelle II dieser mit Tabelle XI der vorigen Mitteilung vergleichen.

Tabelle II a.

Respiratorische Quotienten ${ }^{1}$ ) nach Alkoholgenuss.

\begin{tabular}{c|c|c|c|c}
\hline $\begin{array}{c}\text { Versuchs- } \\
\text { strecke }\end{array}$ & Versuch 33 & Versuch 35 & Versuch 36 & Versuch 40 \\
\hline Tramosner Tobel & & & & \\
I & 0,753 & 0,822 & 0,845 & 0,801 \\
II & 0,778 & 0,833 & 0,817 & 0,823 \\
III & 0,776 & 0,858 & 0,803 & 0,799 \\
Gipfel & 0,811 & 0,864 & 0,806 & 0,796 \\
\hline
\end{tabular}

1) Die Spalten sind beim Vergleich von oben nach unten zu lesen. 
Tabelle II b.

Tab. XI aus Mitt. II. Respiratorische Qnotienten bei Normalversuchen.

\begin{tabular}{c|c|c|c|c}
\hline \hline $\begin{array}{c}\text { Versuchs- } \\
\text { strecke }\end{array}$ & Versuch 32 & Versuch 35 & Versuch 37 & Versuch 38 \\
\hline & 0,869 & 0,855 & 0,776 & 0,805 \\
I & 0,856 & 0,853 & 0,762 & 0,796 \\
II & 0,833 & 0,852 & 0,757 & 0,775 \\
III & 0,832 & 0,838 & 0,745 & 0,756
\end{tabular}

Der in der senkrechten Fortsetzung jeder Kolumne von II a in Tabelle II b eingesetzte Versuch ist der zugehörige Kontrollversuch.

Während in Versuch 33 die Quotienten von einem niedrigsten Wert mit dem Aufsteigen in die Höhe kontinuierlich anwachsen, sinken sie in Versuch 32 von dem hohen Wert 0,860 ständig bis auf 0,832 $a b$, in beiden Reihen somit genau das entgegengesetzte Verhalten. Geradeso verhält sich Versuch 35 gegenüber Versuch 34 ; im Alkoholversuch das ständige Anwachsen, im Normalversuch der Abfall. Der erste Wert von Nr. 36 macht eine Ausnahme, die nicht erk]ärlich ist, im übrigen haben wir diesmal zwar keinen Abíall, aber ein Konstantbleiben gegenüber dem in Versuch 37 ausgesprochenen deutlichen Abfall der Quotienten, dasselbe zeigt Versuch 40; in Übereinstimmung damit steht die Tatsache, dass im allgemeinen der Quotient im letzten Versuch der Alkoholreihe höher steht als im letzten Versuch der Normalversuchsreihe, wobei nur Versuch 32, der mit einem ausserordentlich hohen Quotienten im Normalversuch einsetzt, eine Ausnahme macht. Es ist bereits oben erwähnt, dass dieser Quotient durch die vorherige längere Versuchs-Marschpause leicht begründet werden kann.

Wir haben oben in Übereinstimmung mit Zuntz das Abfallen der respiratorischen Quotienten dahin gedeutet, dass es als Zeichen des fortschreitenden Verbrauchs der Kohlehydrate während der Marschleistung aufzufassen ist.

Diesem Verbrauch der Kohlehydrate begegnen wir nun hier in den Alkoholversuchen nicht, der Quotient bleibt konstant, ja wir finden am Ende des Aufstieges manchmal Quotienten, weiche die Höhe des (allerdings nicht unmittelbar vergleichbaren) Quotienten am Be$\mathrm{g}$ in $\mathrm{n}$ e des Kontrollversuches erreichen oder übertreffen. Wir wissen nun, dass Alkoholverbrennung den respiratorischen Quotienten herabdrückt und müssen aus den verschiedensten Erscheinungen ableiten, 
dass er auch leicht und rasch verbrennt; beachten wir nun die anfänglich niederen und später höheren Quotienten oder das Fehlen der Verminderung in den Quotienten im Laufe des Aufstieges, das sonst den allmählichen Verbrauch der Kohlehydrate und reichlicheres Heranziehen von Fett zu den Oxydationsprozessen im Normalversuch begleitet, so zwingt uns die Tatsache, unsere Annahme fallen zu lassen, dass der ganze Alkohol nach dem Anmarsch bereits verbrannt gewesen sei, und wir müssen wohl ohne Frage die Quotienten so beurteilen, dass sie anfänglich durch die Verbrennung von Alkohol stärker gedrückt sind und in dem Masse, als immer mehr und mehr Alkohol verbrannt ist und weniger davon mehr oxydiert werden konnte, immer reichlicher die Kohlehydrate zur Oxydation herangezogen wurden, so dass die Quotienten anstiegen und wir schliesslich, wenn der Alkoholganz oder fast ganzverbrannt war, respiratorische Quotienten fanden, wie wir sie im Beginne des Aufstieges im Normalversuch sahen.

Wenn die Versuche 36 und 40 dieses Ansteigen nicht mehr zeigen, so zeigt doch das Feblen des Abfalls des Quotienten und die relative Höhe, die dieser am Schluss aufweist, dass ähnliche Dinge im Spiele sein müssen, ja wir können fast sagen, wir wissen, dass sie bestehen müssen, denn die Quotienten in den Versuchen 37 und 38 sind überhaupt vom Beginn an niedrig. Wir haben Reihen von rasch aufeinanderfolgenden Versuchsmärschen vor uns, in denen die Koblehydrate sich nicht rasch genug ersetzen konnten, darum die niederen Quotienten und deren tiefer Abfall in Versuch 37 und 38; in Versuch 36 und 40 liegen die Werte aber durchgehends höher als in den Kontrollen, und die Endwerte können im Alkoholversuch um dasselbe höher gegenüber dem Normalversuch angesehen werden, um was sie in den Versuchen 33 und 35 anstiegen, so dass wir im Prinzip, nur geändert durch einen geringeren Kohlehydratvorrat des Körpers, in allen vier Versuchen der Alkoholreihe demselben Verhalten begegnen. Können wir auf Grund dieser relativ wenigen Versuche, die allerdings eine ganz überraschende, und ich muss gegestehen, mir unerwartete Gesetzmässigkeit ergaben, die sich zu dem Verhalten der Quotienten im Normalversuch in direkten Gegensatz stellt, auch das Wort "Beweis" nur mit Vorbehalt aussprechen, und ich hoffe bald noch gefestigtere Belege auf diesem Wege fort- 
schreitend erbringen zu können, so ist die Annahme von weitergehender Bedeutung dadurch gerechtfertigt, dass Kohlehydrate, die sonst bereits im ersten Teil des Anstieges verbraucht worden wären, am Schlusse des Aufstieges noch zur Verfügung standen und der Organismus als leichter oxydables Material, dessen er sich vielleicht auch lieber rasch zu entledigen trachtet (sit venia verbo), $\mathrm{zuerst}$ den Alkohol oxydiert und dadurch an Kohlehydraten spart, so dass also wenigstens ein Teil der zugeführten 177000 bezw. 233000 Cal., die der Brennwert des Alkohols repräsentiert, in direkter oder indirekter Weise für die Leistung nutzbringender Arbeit herangezogen wurde. Diese Tatsache ist wichtig genug, um sich weiter mit ihr zu befassen, da der Weg auch in dieser Hinsicht ein viel mehr versprechender geworden ist, als ich anfangs gedacht hatte. Wenn wir damit die Tatsache fast sicher in Händen haben, dass die Maschine, mit Alkohol geheizt, läuft und Arbeit leistet, so soll das Folgende uns zeigen, wie sie ihre Arbeit mit dem ungewohnten Brennmaterial verrichtet, denn damit allein, dass Alkohol für die Leistung von Arbeit verbrannt wird, ist noch nichts über die zweckmässige Verwertbarkeit des Alkohols für Muskelarbeit gesagt.

Auch über diese Verhältnisse gibt uns die Generaltabelle nur schwer Auskunft, es sollen daher die folgenden beiden Hilfstabellen einen Vergleich zwischen der Geschwindigkeit und der Steigung, die während des Marsches im Alkoholversuche erreicht bezw. zurückgelegt wurde, mit den Normalversuchen ermöglichen. Hervorgehoben muss werden, dass Versuch 40 nach Genuss von $40 \mathrm{ccm}$ Alkohol durchgefübrt worden ist.

(Siehe Tabelle III und IV auf S. 378.)

Zur Erleichterung des Einblickes ist in allen Versuchen der per Minute im Alkoholversuch zurückgelegte Weg von demjenigen subtrahiert, der im zugehörigen Normalversuch per Minute gegangen wurde, dasselbe gilt für die Steigung. Es ergibt sich, dass in allen Versuchen, in denen Alkohol genossen wurde, der Weg ein geringerer ist als im zugehörigen Normalversuch, ebenso bleibt auch die Steigung im Alkoholversuch hinter dem Normalversuch stets zürück, und zwar nicht nur um Werte, die in den Bereich des Zufalls gehören, sondern ganz einheitlich konstant sind, ja sogar eine ganz ähnliche Grössenordnung aufweisen. Nicht eine einzige Abweichung besteht in diesem Verhalten. 

A. Durig:

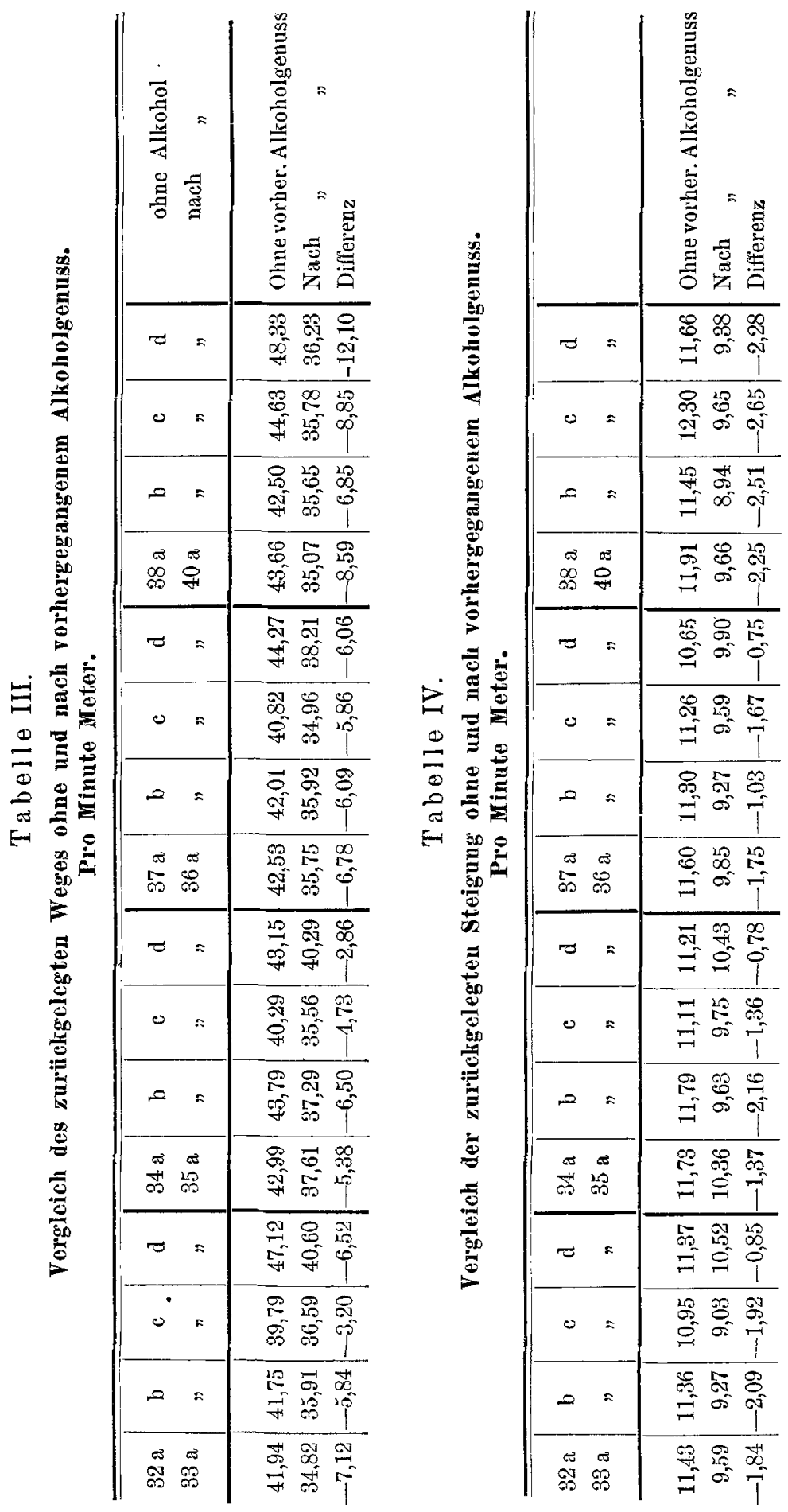


Um die Tatsache anschaulicher zu machen, wurde jeder Differenzwert mit negativen Vorzeichen versehen (natürlich ist der Rest durch die Subtraktion der Alkoholwerte vom Normalversuch ein positiver), um zu zeigen, dass Weg und Steigung pro Minute im Alkoholversuch geringer sind als im Normalversuch.

Diese Gesetzmässigkeit ist von Bedeutung; denn sie legt fest, dass man im Alkoholversuch, ohne sich dessen bewusst zu werden, in derselben Zeit um 12-14\% an Weg und Steigung weniger leistet als im Normalversuch. Nichtsdestoweniger ist die Summe der für die Arbeit aufgewendeten Kalorien gegenüber der Norm nicht in dem Masse gesunken, als dies der Verminderung der Arbeit entspricht. Über diese Verhältnisse gibt die letzte Kolumne der Tab. I und übersichtlich Tab. V Aufschluss, die einen Vergleich über Effekt und Wirkungsgrad ermöglicht.

Tabelle V.

Übersicht über die gesamte Arbeitsleistung beim Steigen nach Alkoholgenuss.

\begin{tabular}{|c|c|c|c|c|c|c|c|}
\hline Nr. & $\begin{array}{c}\text { per Minute } \\
\text { Horizontal- } \\
\text { bewegung } \\
\text { Kilo mal } \\
\text { Meter }\end{array}$ & $\begin{array}{c}\text { Die } \\
\text { horizontale } \\
\text { Fortbe- } \\
\text { wegung von } \\
1 \mathrm{~kg} \text { entlang } \\
1 \mathrm{~m} \text { ent- } \\
\text { spricht mkg } \\
\text { (Steigarbeit) }\end{array}$ & $\begin{array}{l}\text { Die gesamte } \\
\text { horizontal } \\
\text { geleistete } \\
\text { Arbeit per } \\
\text { Minute ent- } \\
\text { spricht mkg } \\
\text { (Steigarbeit) }\end{array}$ & $\begin{array}{l}\text { Steigar- } \\
\text { beit per } \\
\text { Minute } \\
\text { mkg }\end{array}$ & \begin{tabular}{|} 
Gesamte \\
Arbeit per \\
Minute \\
mkg \\
für Steigung \\
und \\
Horizontal- \\
bewegung
\end{tabular} & $\begin{array}{l}\text { Effekt } \\
\text { P. S. }\end{array}$ & $\begin{array}{c}\text { Wir- } \\
\text { kungs- } \\
\text { grad } \\
\%\end{array}$ \\
\hline $\begin{array}{r}33 \mathrm{a} \\
\mathrm{b} \\
\mathrm{c} \\
\mathrm{d}\end{array}$ & $\begin{array}{l}2835 \\
2923 \\
2977 \\
3304\end{array}$ & $\begin{array}{l}0,06642 \\
0,06586 \\
0,07335 \\
0,07177\end{array}$ & $\begin{array}{l}188,3 \\
192,5 \\
213,4 \\
231,3\end{array}$ & $\begin{array}{l}780,8 \\
754,0 \\
816,0 \\
855,4\end{array}$ & $\begin{array}{r}969,1 \\
947,5 \\
1029,8 \\
1086,7\end{array}$ & $\begin{array}{l}0,2105 \\
0,2105 \\
0,2288 \\
0,2415\end{array}$ & $\begin{array}{l}24,3 \\
24,1 \\
26,2 \\
25,6\end{array}$ \\
\hline $\begin{array}{rl}35 & \mathrm{a} \\
\mathrm{b} \\
\mathrm{c} \\
\mathrm{d}\end{array}$ & $\begin{array}{l}3047 \\
3021 \\
2881 \\
3262\end{array}$ & $\begin{array}{l}0,06739 \\
0,07019 \\
0,07048 \\
0,07225\end{array}$ & $\begin{array}{l}205,3 \\
212,1 \\
205,0 \\
236,0\end{array}$ & $\begin{array}{l}839,3 \\
779,8 \\
790,0 \\
845,0\end{array}$ & $\begin{array}{r}1044,6 \\
991,9 \\
993,0 \\
1081,0\end{array}$ & $\begin{array}{l}0,2322 \\
0,2204 \\
0,2207 \\
0,2403\end{array}$ & $\begin{array}{l}24,6 \\
25,7 \\
25,7 \\
25,8\end{array}$ \\
\hline $\begin{array}{rl}36 & \mathrm{a} \\
\mathrm{b} \\
\mathrm{c} \\
\mathrm{d}\end{array}$ & $\begin{array}{l}2896 \\
2977 \\
2898 \\
3163\end{array}$ & $\begin{array}{l}0,07074 \\
0,07193 \\
0,07327 \\
0,07285\end{array}$ & $\begin{array}{l}204,9 \\
214,1 \\
212,3 \\
230,7\end{array}$ & $\begin{array}{l}816,3 \\
768,5 \\
794,6 \\
820,5\end{array}$ & $\begin{array}{r}1021,3 \\
982,6 \\
1006,9 \\
1061,2\end{array}$ & $\begin{array}{l}0,2270 \\
0,2184 \\
0,2238 \\
0,2358\end{array}$ & $\begin{array}{l}25,8 \\
26,3 \\
26,8 \\
26,6\end{array}$ \\
\hline $\begin{array}{rl}40 & \mathrm{a} \\
\mathrm{b} \\
\mathrm{c} \\
\mathrm{d}\end{array}$ & $\begin{array}{l}2898 \\
2862 \\
2908 \\
2994\end{array}$ & $\begin{array}{l}0,06651 \\
0,07030 \\
0,07113 \\
0,07282\end{array}$ & $\begin{array}{l}192,8 \\
201,3 \\
206,8 \\
218,0\end{array}$ & $\begin{array}{l}798,5 \\
738,7 \\
797,3 \\
775,6\end{array}$ & $\begin{array}{r}991,3 \\
939,0 \\
1004,1 \\
993,6\end{array}$ & $\begin{array}{l}0,2203 \\
0,2087 \\
0,2231 \\
0,2208\end{array}$ & $\begin{array}{l}24,3 \\
25,7 \\
26,0 \\
26,6\end{array}$ \\
\hline
\end{tabular}

Setzen wir mit vorstehender Tabelle die Tab. XII der zweiten Mitteilung (S. 266) in eine Parallele, so ergibt sich aus beiden mit voller, 
unumstösslicher Eindeutigkeit, dass nicht nur der Effekt und zwar in jeder einzelnen Strecke, sondern a u ch der Wirkungsgrad (der Quotient aus produzierter Energie und dem Aufwand an Energie für die.Arbeitsleistung) gesunken ist. Zu erwähnen ist bezüglich der Tabelle nur, dass in bezug auf die Berechnung des Effekts dasselbe gilt, was oben bei Tab. XII vorausgeschickt wurde.

Wenn wir die Mittel von Effekt und Wirkungsgrad der Versuche der zweiten Periode, die also auf einen gleichen Zeitabschnitt hinsichtlich der Übung verteilt sind, ordnen, so ergibt sich:

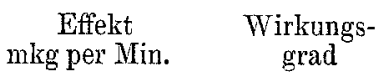

Nach Alkoholgenuss . . . 1009

ohne Alkoholgenuss. . . . 1215

Abnahme durch Alkoholgenuss 206

somit Verlust in Prozenten des

$25,62 \%$ nach Alkoholgenuss,

$29,55 \%$ ohne Alkoholgenuss,

$3,93 \%$ Abnahme durch Alkoholgenuss,

Wertes des Normalversuches

durch Alkoholdarreichung . $20 \%$

$13,3 \%$ somit Verlust in Prozenten des Wertes im Normalversuch.

Trotz einer Abnahme des Effekts um 20\% ist also auch der Wirkungsgrad gesunken und zwar in einer ganz überraschenden Weise. Wir müssen dabei noch ausserdem darauf hinweisen, dass das zu berücksichtigen ist, was bereits oben erwähnt wurde, dass es nicht Maximalwerte des Verbrauchs sind, die wir in Rechnung stellen, wenn wir, anstatt der Tatsache Rechnung zu tragen, dass Alkohol verbrannt wurde, was ich zur Zeit der Ausrechnung der Versuche aus den Zahlen noch nicht entnehmen konnte, den Brennwert für Fett zugrunde gelegt haben. Nachdem wir nun aus dem Verhalten der respiratorischen Quotienten als zwingend annehmen müssen, dass im Versuch auch Alkohol verbrannt ist, so müssen die Werte für die Grösse des Effektes und des Wirkungsgrades sich dann noch ungünstiger gestalten. Die Maschine arbeitete also unter der Einwirkung dieses Feuerungsmaterials nicht nur langsamer, als wenn ihr gewöhnliches Brennmaterial zugeführt worden wäre, sondern bei dem Versuch, sie mit Alkohol zu heizen, ist sie sogar direkt vorübergehend geschädigt worden, indem sie unter geringerer Ausnützung des ihr zu Gebote stehenden Materials weniger Arbeit leistete, wobei ihr also ausser dem schlechten auch noch ein teurer Brennstoff zugeführt wurde. 
Versuchen wir nun, um uns ein Bild über die Rolle, die die Alkoholverbrennung im Haushalt spielen kann, zu verschaffen, einen Vergleich zwischen dem zu ziehen, was wir an Kalorien durch die Zufuhr von Alkohol gewannen, unter der noch nicht bewiesenen, für den Alkohol günstigsten Voraussetzung, diese seien sämtlich nutzbar verwertet worden, und zwischen jenen Verlusten, die dem Organismus in dem Absinken von Wirkungsgrad und Effekt im Alkoholversuch erwachsen sind, für die er mit Mehrausgaben aufkommen muss, soll er die nämliche Arbeit leisten wie im Normalversuch.

Dem verringerten Effekt entspricht eine grössere Marschzeit, die, wie erwähnt, in den Alkoholversuchen bis zum Tramosner Tobel 10 Minuten, bis zum Gipfel 25 Minuten betrug. Für die Berechnung setzen wir voraus, dass die Arbeit auf dem ganzen Wege von der Hütte im Normalversuch wie im Alkoholversuch jeweilig in derselben Art geleistet wurde, wie wir dies durch die Bestimmungen im Verlaufe des Aufstiegs vom Tramosner Tobel zum Gipfel festgelegt haben.

So entspricht nun der längeren Marschdauer von 25 Minuten bei einer per Minute verausgabten Zahl von 9200 cal. im Mittel eine Mehrausgabe von $25 \times 9200$ cal. $=230000$ cal., dafür war aber im Normalversuche die Ausgabe per Minute entsprechend dem grösseren Effekt eine grössere; sie betrug 10000 cal. per Minute im Mittel gegenüber 9200 cal. per Minute im Alkoholversuch, was einer Differenz von 800 cal. per Minute zu ungunsten des Normalversuchs gleichkommt. Für eine Aufstiegszeit von 1 Stunde 40 Minuten beträgt diese Mehrausgabe daher im Normalversuch $160 \times$ 800 cal. $=128000$ cal., dies ist also die dem grösseren Effekt entsprechende Mehrauslage im Normalversuch gegenüber derselben Marschzeit im Normalversuch, so dass für die Alkoholversuche eine Mehrausgabe von $230000-128000=102000$ cal. trotz der längeren Zeit, die zur Leistung derselben Arbeit erforderlich war, sich ergibt.

Nehmen wir nun an, was ja ganz ausgesehlossen ist (schon darum, weil ein Teil des Alkohols unverbrannt den Körper verlässt), es würden die Kalorien des zugeführten Alkohols in ihrer Gänze, und zwar mit dem vollen Nutzeffekt, wie das sonst im Körper verbrannte Material, das der gewöbnlichen Nahrung entstammt, verwertet werden können, der Alkohol sich also vollständig isodynam mit den Nahrungsmitteln verhalten, so stünden aus der gewiss nicht geringen Dosis von $30 \mathrm{~g}$ Alkohol im Mittel der verwendeten Dosen 
dem Körper insgesamt $7070 \times 30 \mathrm{cal} .=212100 \mathrm{cal}$. zur Verfügung, die den Verlust von 102000 cal. wett machen könnten, wobei noch ein Rest von 110100 cal. erübrigt worden wäre. Selbst bei diesem Ansatz wäre also nur die Hälfte des teuer erkauften und dazu noch mit Schädigungen vorübergehender Art wirkenden Brennmaterials verausgabt worden, um den Schaden, den es anrichtete, zu decken, und erst die restlichen $52 \%$ könnten nun in Arbeit umgewandelt werden, die als praktisch verwertbar in Betracht zu ziehen wären. Bei einem Wirkungsgrad von $22 \%$ würden daher also nur $12 \%$ der Energie des zugeführten Alkohols in Form von durch sie geleisteter Arbeit im allergünstigsten Falle erscheinen können.

Dies ist jedoch nur die eine Seite, die in Betracht zu ziehen ist. Wir müssen berücksichtigen, dass die Zeit, welche für die Durchführung derselben Arbeit erforderlich war, vom Normalversuch mit 2 Stunden 40 Minuten auf 3 Stunden 5 Minuten im Alkoholversuch gesteigert ist. Übertragen wir diese Verhältnisse auf einen Arbeitstag, so würde dieselbe Arbeit ohne Alkoholzufuhr in acht Stunden geleistet worden sein, für die nach Alkoholgenuss rund neun Stunden erforderlich gewesen wären, so dass neben der schlechteren Verwertung des Alkohols als Brennmittel dureh das Auftreten von Mehrausgaben, die erst gedeckt werden mussten, immer noch $\mathrm{zu}$ bedenken ist, dass während einer Stunde Rast bei der ohne Alkohol geleisteten Arbeit nach Alkoholgenuss während dieser Zeit hätte gearbeitet werden müssen, um das Versäumte einzubringen.

Diese Ausführungen, die sich auf dem nicht bewiesenen, für den Alkohol allergünstigsten Fundament aufbauen, dass seine Energie voll und isodynam einem wirklichen Nahrungsmittel für die Muskelarbeit ausgenützt werden könnte, und voraussetzten, dass er auch quantitativ ohne jeden Verlust durch Ausscheidung durch Harn und Lunge verbrannt worden sei, sollten zu einer leichteren Darstellung dienen, uın zu beweisen, dass Alkohol für sich als kein vollwertiges Nahrungsmittel für Muskelarbeit angesehen werden kann, ganz gleichgültig, ob wir nun annehmen, dass er isodynam verwertet werden könne oder nicht; denn wenn auch dem Körper ein nicht unbeträchtlicher Teil der zugeführten Menge über die Decluung des Verlustes zur Verfügung stand, so ist doch durch denVerbrauch, der für die Bestreitung der Mehrausgaben bedingt ist, die praktische Nutzung aus dem zugeführten Alkohol auf die Hälfte eines wirklichen Nahrungsmittels gesunken und zudem 
die Zeit für die Arbeit verlängert worden. Aus der 0,275 PS.Maschine wurde eben eine schlechtere, 0,222 PS.-Maschine mit niedererem Wirkungsgrad.

Diese für mich unter den gegebenen Bedingungen festgestellte Tatsache darf aber ohne weiteres nicht verallgemeinert werden; es wäre irrig, wollte man damit die Frage über die Wirkung des Alkohols bei Muskelarbeit ubberhaupt in dem Sinne beantworten, dass Alkohol nicht vielleicht günstigere Wirkungen als Kraftspender bei Muskelarbeit entfalten könne; vorläufig sind wir über die Tatsache, in welchem Umfange Alkohol bei Muskelarbeit nutzbar herangezogen werden könne, nicht im klaren, ebensowenig wissen wir etwas über den Nutzeffekt, mit dem Alkohol tatsächlich bei Muskelarbeit verbrennt. Darüber gaben uns die Versuche bisher keinen Aufschluss, denn wir konnten nur festlegen, mit welchen Alkoholmengen die für nutzbare Arbeit verwertet werden könnten, wir im äussersten Fall unter gegebenen Verhältnissen bej mir zu rechnen hatten, wobei wir immer noch voraussetzen mussten, es sei der ganze zugeführte Alkohol bis zum Abschluss des Steigungsmarsches tatsächlich verbrannt worden, was man allerdings mit einer gewissen Wahrscheinlichkeit aus den respiratorischen Quotienten ableiten kann.

Anders werden wir die Verhältnisse beurteilen müssen, wenn wir einen Menschen in Betracht ziehen, der wesentlich höhere Alkoholdosen durch Abstumpfung gegen dessen Giftwirkungen konsumieren kann, vielleicht unter Wegfall oder bei geringerer Grösse jener Erscheinungen, die sich in meinen Versuchen als Verminderung des Effektes und des Wirkungsgrades ausgeprägt haben. Darüber Vermutungen aufzustellen, ist müssig, wir sahen, dass Hellsten $80 \mathrm{~g}$ Alkohol $=565600$ Cal. einzuführen vermag, ohne anscheinend dadurch mehr gestört zu werden, als dies bei mir durch $30 \mathrm{~g}$ der Fall war. Ziehen wir bei einer Zufuhr von $80 \mathrm{~g}$ Alkohol einen Wert, wie ich ihn für die Mehrausgaben, bei der Arbeit unter Alkoholwirkung fand, ab, so bleiben immerhin noch $463600 \mathrm{Cal}$. übrig, die für die Verrichtung von Muskelarbeit zur Verfügung ständen; trotz alledem ist der Betrag nicht hoch und würde eben nur hinreichen, den Arbeitsverbrauch bei einigermassen angestrengter Tätigkeit durch etwa eine Stunde zu decken, wenn wir annehmen, dass er hierfür tatsächlich voll und isodynam ausgenützt werden könnte.

Was bedeutet aber eine Leistung von einer Stunde Arbeit gegen 
einen Konsum von ein viertel Liter Schnaps? Es geht also auch aus diesen Anführungen hervor, dass Alkohol im günstigsten Falle ein teilweiser Ersatz von Nahrungsmitteln bei Muskelarbeit sein kann, dass aber jedenfalls ganz gewaltige Dosen erforderlich sind, die auf die Dauer nur mit schweren Schädigungen des Organismus genossen werden können, die für die Leistung nennenswerter Arbeit in Betracht kommen. Für den an mässige Gaben gewöhnten Menschen wird seine erfolgreiche Verwertung aber noch stärker durch Mehrausgaben herabgesetzt, die mit seiner Giftwirkung in Zusammenhang stehen.

Diese letzten Auseinandersetzungen, bei denen wir den Boden der festgesteiltèn Tatsachen teilweise veriassen mussten, erbringen den Beweis, wie wichtig es ist, die Versuche über den Einfluss des Alkohols auf die Arbeitsleistung und die Studien über die Frage nach der Ausnützung der aus der Verbrennung von Alkohol sich entwickelnden Energie an Personen durchzuführen, die reichlichen Aikoholgenuss gewöhnt sind, und bei knapper Nahrung doch sehwere Arbeit leisten, um so mehr als unsere theoretische Ableitung auch für sie nicht zugunsten einer rationellen Ausnutzbarkeit der Energie des Alkohols spricht. Ich hoffe in Bälde auch diese Untersuchungen nachtragen zu können und das vorläufig nur an einer Person, die mässigen Aikoholgenuss gewöhnt ist, gewonnene Resultat erweitern zu können. Sicher müssen wir noch weiter betonen, dass auch das Verhalten eines Durchschnittsmenschen, als welcher die Versuchsperson angesehen werden muss, noch keinen individuellen Schwankungen Rechnung trägt, wie wir diese bei der Untersuchung mehrerer anscheinend ganz gleichwertig eỉnzuschätzenden Durchschnittsmenschen wohl sicher kennen lernen würden.

Gehen wir in der Besprechung unserer Tabellen weiter und stellen wir wie die in bezug auf Weg und Steigung erbaltenen Resultate auch die Verbrauche für die Arbeit beim Normalversuch und nach Alkoholgenuss zusammen, indem wir num dem Einfluss der Alkoholgabe in den einzelnen Versuchsstrecken folgen.

Tabelle 6 enthält den Umsatz per Meterkilogramm Arbeit in den Alkoholversuchen und die entsprechenden Werte aus Generaltabelle II der vorigen Mitteilung. In allen Versuchen ist der Verbrauch im Normalversueh geringer als im Alkoholversuch, so dass nun, wenn wir den Normalversuchswert vom Alkoholversuchswert abziehen, eine Differenz

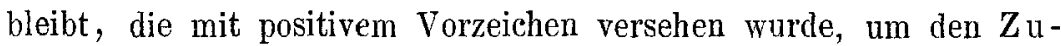
wachs an Verbrauch für das Meterkilogramm Arbeit im Alkohol- 
versuch zu kennzeichnen. Gruppieren wir diese Differenzen nach den einzelnen Versuchsstrecken, so gewinnen wir einen Einblick in das Verhalten der Alkoholwirkung in derselben Versuchsstrecke, aber an verschiedenen Versuchstagen, wie wir auch den Verlauf der Wirkung während eines jeden Aufstieges besser übersehen.

Tabelle VI.

Vergleich des Verbrauches für $1 \mathrm{mkg}$ Steigarbeit in Kalorien beim Marsch mit und ohne rorangegangenen Alkoholgenuss. (Pro mkg Arbeit cal.)

\begin{tabular}{|c|c|c|c|c|c|c|c|c|}
\hline $\begin{array}{l}32 \mathrm{a} \\
33 \mathrm{a}\end{array}$ & $\begin{array}{l}\mathrm{b} \\
y\end{array}$ & $\mathrm{c}$ & $\begin{array}{l}\mathrm{d} \\
\eta\end{array}$ & $\begin{array}{l}34 \mathrm{a} \\
35 \mathrm{a}\end{array}$ & $\begin{array}{l}\mathrm{b} \\
n\end{array}$ & c & $\mathrm{d}$ & $\begin{array}{l}\text { ohne Alkohol } \\
\text { mit } "\end{array}$ \\
\hline $\begin{array}{r}8,020 \\
9,653 \\
+1,633\end{array}$ & $\begin{array}{r}7,959 \\
9,735 \\
+1,776\end{array}$ & $\begin{array}{r}8,078 \\
8,945 \\
+0,867\end{array}$ & $\begin{array}{r}8,084 \\
9,160 \\
+1,076\end{array}$ & $\begin{array}{r}7,929 \\
9,513 \\
+1,584\end{array}$ & $\begin{array}{r}7,665 \\
9,123 \\
+1,458\end{array}$ & $\begin{array}{r}7,949 \\
9,097 \\
+1,148\end{array}$ & $\begin{array}{r}7,991 \\
9,069 \\
+1,078\end{array}$ & $\begin{array}{l}\text { Ohne Alkoholgenus } \\
\text { Nach " } \\
\text { Differenz. }\end{array}$ \\
\hline
\end{tabular}

\begin{tabular}{|c|c|c|c|c|c|c|c|c|}
\hline $\begin{array}{l}37 \mathrm{a} \\
36 \mathrm{a}\end{array}$ & $\begin{array}{l}\mathrm{b} \\
\eta\end{array}$ & $\begin{array}{l}\mathrm{c} \\
\eta\end{array}$ & $\begin{array}{l}\mathrm{d} \\
\#\end{array}$ & $\begin{array}{l}38 \mathrm{a} \\
40 \mathrm{a}\end{array}$ & b & $\begin{array}{l}\mathrm{c} \\
\eta\end{array}$ & d & $\begin{array}{l}\text { ohne Alkohol } \\
\text { nach }\end{array}$ \\
\hline $\begin{array}{r}7,898 \\
9,062 \\
+1,164\end{array}$ & $\begin{array}{r}7,757 \\
8,913 \\
+1,156\end{array}$ & $\begin{array}{r}7,959 \\
8,750 \\
+0,891\end{array}$ & $\begin{array}{r}8,000 \\
8,801 \\
+0,801\end{array}$ & $\begin{array}{r}7,912 \\
9,639 \\
+1,727\end{array}$ & $\begin{array}{r}7,854 \\
9,127 \\
+1,273\end{array}$ & $\begin{array}{r}7,906 \\
9,015 \\
+1,109\end{array}$ & $\begin{array}{r}7,989 \\
8,864 \\
+0,875\end{array}$ & $\begin{array}{l}\text { Ohne Alkoholgenus } \\
\text { Nach " } \\
\text { Differenz. }\end{array}$ \\
\hline
\end{tabular}

Tabelle VII.

Vergleich der Differenzen des Kalorienverbrauchs in den Versuchsstrecken (cal. per mkg Steigarbeit).

\begin{tabular}{c|c|c|c|c}
\hline \multirow{2}{*}{$\begin{array}{c}\text { Für } \\
\text { Versuchs-Nr. }\end{array}$} & \multicolumn{4}{|c}{ Versuchsstrecke } \\
\cline { 2 - 5 } & $\begin{array}{c}\text { I } \\
\text { Tram.-Tobel } \\
\text { cal. }\end{array}$ & II & III & $\begin{array}{c}\text { IV } \\
\text { Gipfel } \\
\text { cal. }\end{array}$ \\
\hline & & & cal. & \\
33 & 1,633 & 1,776 & 0,867 & 1,076 \\
35 & 1,584 & 1,458 & 1,148 & 1,078 \\
36 & 1,164 & 1,156 & 0,891 & 0,801 \\
40 & 1,723 & 1,273 & 1,109 & 0,875
\end{tabular}

Mit ganz geringfügigen Abweichungen ergeben sich einheitlich aus der Tabelle neue Gesichtspunkte, die wir den Zahlen bisher nicht entnehmen konnten. Wir müssen bei unserer Betrachtung Versuch 33, 35 und 36 , die nach einer Alkoholdosis von $30 \mathrm{ccm}$ gewonnen wurden, trennen von Versuch 40 , vor dem $40 \mathrm{ccm}$ Alkohol eingeführt wurden. Sämtliche Werte der ersten Reihe zeigen einmal in den Spalten von links nach rechts gelesen die Tendenz von einem höchsten Wert im Beginne zu einem niederen Wert am Ende der 
Versuchsreihe, also in der obersten dem Gipfel zu gelegenen Strecke abzusinken; auch der Versuch 40 mit grösserer Alkoholdosis macht hiervon keine Ausnahme. Wir finden also, dass die Verschlechterung des Wirkungsgrades, die sich nach Alkoholgenuss eingestellt hat, je länger die Versuchsperson ging und je mehr vom Alkohol verbrannt wurde, um so weniger geltend gemacht hat und der Verbrauch für das Meterkilogramm Arbeit im Alkoholversuch sich dabei immer mehr dem Verbrauch im Normalversuch näherte. Ganz im Gegensatz dazu haben wir im Normalversuch festlegen können, dass der Energieverbrauch in der letzten Strecke sich gegenüber den übrigen fast stets als höher erwies, woraus wir hinsichtlich der Alkoholversuche nun bindend den Schluss ziehen können, dass die Erscheinung, die wir bei diesen beobachteten, nicht auf eine Höhenwirkung zurückzuführen ist. Für die Erklärung dieser gefundenen Tatsache können wir nur einerseits annehmen, dass die Arbeit mit dem Abklingen der Alkoholwirkung günstiger durchgeführt wurde, zwecklose überschüssige Bewegungen vermieden waren und durch bessere Aufmerksankeit auf die Beschaffenheit des Weges auch geschickter gegangen wurde. Andererseits müssen wir erwägen, $o b$ die Verminderung des Kalorienumsatzes und dadurch die Ausgabe von weniger Energie für die Leistung von $1 \mathrm{mkg}$ Arbeit nicht dadurch bedingt gewesen ist, dass der Alkohol, der neben dem Umsatz der Nährstoffe, die nach wie vor, ganz unbeeinflusst dureh das Vorhandensein von Alkohol, oxydiert wurden und den Verbrauch für die Arbeit decken mussten, verbrannte, ohne irgendwie oder nur in ganz geringem Grade für die Arbeitsleistung selbst herangezogen zu werden. In diesem Falle hätten die als nutzlos aus dem Körper hinausgeworfenen Kalorien des Alkohols, die zu der Arbeit in keine Beziehung traten, wohl den kalorischen Umsatz per Minute gesteigert, dabei wäre aber die Arbeit dieselbe geblieben und dadurch die Ausgabe für das Meterkilogramm Arbeit um so höher geworden, je mehr Alkohol verbrannt wurde, mit der Elimination des Alkohols aus dem Organismus hätte dann naturgemäss ebenfalls der Umsatz pro. Meterkilogramm Arbeit sinken müssen.

Bei einem Einblick in die vorliegenden Verhältnisse müssen wir letztere Möglichkeit in zweite Linie stellen und der ersteren Voraussetzung grössere Berechtigung einräumen. Ist es schon nicht wahrscheinlich, dass die Menge von Alkohol, die in der Minute oxydiert wird, so sehr von der Menge abhängig sein soll, die noch im Körper 
vorhanden ist und oxydiert werden muss, so besagt uns die Tabelle weiter, dass dann die Ausscheidung und Oxydation von Alkohol nit der vierten Versuchsstrecke noch lange nicht vollendet sein dürfte, ja erst etwa die Hälfte betragen könnte, nachdiem die Differenz im Umsatz erst auf die Hälfte abgesunken ist. Dass Alkohol in der letzten Versuchsstrecke aber tatsächlich nicht mehr oder nur mehr in vermindertem Masse verbrannt worden sein kann, besagen mit grösster Wahrscheinlichkeit, die schon an Gewissheit grenzt, die respiratorischen Quotienten, die fast so hoch geworden sind wie im zugehörigen Normalversuch im Beginne des Aufstieges. Wir haben bei Besprechung dieser Tatsache an der Hand von Tabelle II bereits hervorgehoben, dass kaum eine andere Erklärung möglich sein dürfte als die, dass das Zustandekommen der hohen respiratorischen Quotienten am Schluss des Alkoholversuchs dahin zu deuten ist, dass noch mehr an Kohlehydrat für die oxydativen Prozesse zur Verfügung stand als im Normalversuch, also dureh Alkohol Kohlehydrat erspart und Alkohol selbst zur Leistung von Arbeit herangezogen wurde. Daraus muss die Annahme, dass es ein Abklingen der Giftwirkung ist, dem wir hier in Tabelle VII begegnen, als die berechtigtere und wohl auch naheliegendere erscheinen, neben der ja auch für die zweite Möglichkeit noch Raum ist, dass der Alkohol mit geringerem Nutzwert verbrannt wurde und die Ausgabe an Kalorien pro Meterkilogramm daher überhaupt durehgehends höher ausfallen musste.

Aber nicht nur die nebeneinander liegenden Werte von Tab. VII zeigen eine Gesetzmässigkeit, sondern wir finden eine solche auch in den untereinander stehenden Grössen im Verlauf der ersten drei Versuche. Die Deutung dieses Verhältnisses ist eine naheliegende. Von Versuchstag zu Versuchstag findet eine Gewöhnung an den Alkoholgenuss statt, und die Nachwirkungen werden daher weniger auffällig. Die Tatsache, dass dieser Ausdruck der Abstumpfung gegen die Giftwirkung in der ersten Versuchsstrecke am ausgesprochensten ist, aber immer geringer wird, je höher die Versuchsstrecke liegt, und fast verschwindend in der vierten Strecke ist, steht damit in einem recht befriedigenden Zusammenhange, denn wir können daraus, ohne stark hypothetisch zu sein, entnehmen, dass es die gröberen, mechanischen Störungen durch den Alkohol sind, die sich zuerst durch die Gewöhnung beheben, die sich in der allerersten Zeit nach dem ungewohnten Genuss einstellen, wogegen sich 
die feinen Änderungen in der Form der Bewegung viel länger halten werden, vielleicht auch bei langdauernder Gewöhnung nicht verschwinden. Diese Tatsache, dass eine Gewöhnung und $A b$ stumpfung gegen die Giftwirkung stattfindet, ist eine neue Stütze für die oben erörterte erste Annahme, durch die wir zum Verständnis des Absinkens des Verbrauchs im Verlaufe des Aufstiegs zu gelangen trachteten, da dann, wenn die Verminderung des Vèrbrauchs im Laufe der einzelnen Versuchstage nicht in dieser Weise erklärt werden dürfte, nur mehr die Annahme übrig bleiben könnte, dass der Organismus seine Gewöhnung an den Alkohol dadurch kennzeichnet, dass er ihn nun langsamer verbrennt und das Gift länger zurückbehält. Viel wahrscheinlicher ist es doch anzunehmen, dass die Gewöhnung an eine Giftwirkung sich in jener Zeit am deutlichsten ausprägen muss, in der der Effelit der Giftwirknng der grösste war, wie dies der der Zufuhr am nächsten gelegenen Zeit entspricht.

Versuch 40 liefert uns eine Bestätigung der Annahmen. Hier wurden anstatt $30 \mathrm{ccm} 40 \mathrm{ccm}$ Alkohol gegeben, die Schädigung ist wieder in voller Grösse ausgeprägt, wie im ersten Versuch 33. Auch in allen späteren Versuchsstrecken hält sich die Differenz höher als in den entsprechenden Versuchen der früheren Reihen, trotzdem selien wir aber die Giftwirkung rascher abklingen als in dem ersten Versuch (33), so dass der Erfolg der Anpassung an die Giftwirkung auch aus diesem letzten Versuch noch entnommen werden kann, der in seiner vierten Strecke sicher einen wesentlich höheren Verbrauchswert aufgewiesen bätte, wenn nicht die früheren Versuche mit Alkoholgenuss vorangegangen wären.

Dass ein sonst an ähnliche Alkoholdosen gewöhnter Mensch trotzdem noch derartige Erscheinungen aufweisen kann, erscheint mir selbstverständlich. Die Versuchsperson leistete nach einer Alkoholzufuhr sonst wie Arbeit und vermeidet immer dann, wenn noch eine Arbeitsleistung folgen soll, den Alkoholgenuss, entsprechend der subjektiven Erfahrung einer Herabsetzung geistiger und körperlicher Leistungsfähigkeit selbst nach geringen, im Verlaufe der Tagesarbeit genommenen Alkoholdosen. Wenn die Versuchsperson nun, ganz entgegen ihrer Gewohnheit, nach Alkoholgenuss Arbeit leisten soll, so dass die subjektiv empfundene grössere Ungeeignetheit für die Durchführung von Arbeit in der Änderung von Effekt und Wirkungsgrad objektiv zum Ausdruck gelangt, so ist eine Anpassung an die Verbält- 
nisse gut denkbar. Was durch Übung erreicht werden kann, haben wir in der vorigen Mitteilung ausführlich erörtert und sind dabei wesentlichen Änderungen im Umsatz begegnet, es darf daher nicht wundernehmen, wenn wir bei einer Gewöhnung an eine sonst für die Versuchsperson nicht geläufige Zufuhr von Alkohol am frühen Morgen und der Notwendigkeit, hernach Arbeit zu leisten, ein Abfallen des Verbrauchs als Zeichen dieser Anpassungserscheinung ausgeprägt finden. Denken wir an die unregelmässigen Reihen der Ergographenkurven von Hellsten nach Alkoholgenuss und an die geänderte Form der Kurve des einzelnen Hubes zurück, so ist es wohl selbstverständlich, dass durch eine Abstumpfung der Empfindlichkeit gegen die Giftwirkungen des Alkohols bei einer ungleich komplizierteren Bewegung, wie es der Marsch im Gebirge ist, eine wesentliche Ersparnis in den Ausgaben erzielt werden kann.

Tabelle VIII.

\begin{tabular}{c|c|c|c|c}
\hline $\begin{array}{c}\text { Versuchs- } \\
\text { strecke }\end{array}$ & $\begin{array}{c}\text { Im Mitte] } \\
\text { Weg } \\
\text { pro Minute }\end{array}$ & $\begin{array}{c}\text { Im Mittel } \\
\text { Steigung } \\
\text { pro Minute }\end{array}$ & $\begin{array}{c}\text { Im Mittel } \\
\text { cal. pro mkg } \\
\text { Steigarbeits- } \\
\text { verbrauch }\end{array}$ & $\begin{array}{c}\text { Mittlerer } \\
\text { Wirkungs- } \\
\text { grad }\end{array}$ \\
\hline & & & & \\
II & 35,81 & 9,87 & 9,468 & 2,475 \\
III & 38,19 & 9,28 & 9,222 & 2,545 \\
IV & 35,57 & 9,75 & 8,952 & 2,617 \\
& 38,84 & 10,08 & 8,973 & 2,617
\end{tabular}

Berechnen wir die Mittel der Wege und Steigungen, in den einzelnen Strecken, sowie das Mittel der Ausgaben für das Meterkilogramm Steigarbeit und den Wirkungsgrad, so gewinnen wir einen Überblick, wie sich Leistung und Ausgabe im Durchschnitt im Verlaufe des Aufstieges verhielten. Für den Normalversuch hatten wir festgestellt, dass in der ersten Versuchsstrecke meist ein „Eingehen" erforderlich ist, das von einem höheren Verbrauch als in den späteren Strecken begleitet ist; auch die letzte Versuchsstrecke zeigte ein neuerliches Ansteigen des Umsatzes, das sich als Überverbrauch kennzeichnete, entsprechend dem schnelleren Vorwärtseilen, um das Ziel zu erreichen. Ähnliches finden wir hier im Alkoholversuch, doch verhält sich der Wirkungsgrad von den Normalversuchen ganz abweichend. Die geringeren Verschiebungen, die im Normalversuch zum Ausdruck gelangten, sind hier durch die viel eingreifendere Änderung des Abklingens der Giftwirkung in den Hintergrund gedrängt, so dass trotz einer Zunahme der Geschwindigkeit, 
die in dem letzten Versuch sich ebenfalls ausdrückt, ein Ansteigen des Wirkungsgrades gegenüber dem Versuchsbeginn ausgesprochen bleibt; allerdings bat diese Zunahme, der wir bis zu Versuebsstrecke 3 begegnen,. Halt gemacht und ist ein Stillstand in der Besserung der Arbeitsleistung eingetreten, der im selben Sinne gedeutet werden muss wie das Absinken im Normalversuch. Hier haben sich dann die Mehrausgabe durch die gesteigerte Leistung und die Verminderung durch die Abnahme der Alkoholwirkung eben das Gleichgewicht gehalten.

Die ständige Abnahme der Ausgaben pro Meterkilogramm Arbeitsleistung, der wir im Verlauf des Aufstiegs begegnen, ist also übereinstimmend mit dem, was Hellsten hinsichtlich des Abklingens der Alkoholwirkung am Ergographen beobachtete, eingetreten, nur dass in unserem Falle nicht der Effekt es war, der in ein und derselben Reihe um geringe Grössen schwankte, sondern der Aufwand für dieselbe Leistung, der das Abklingen der Wirkung bereits zwei Stunden nach der Alkoholzufuhr erkennen liess.

\section{Tabelle IX.}

Versuchsstrecke I. Steigung $27 \%$ im Mittel.

\begin{tabular}{|c|c|c|c|c|}
\hline $\mathrm{Nr}$. & Tag & $\begin{array}{c}\text { Weg } \\
\text { pro Minute }\end{array}$ & $\begin{array}{c}\text { Steigung } \\
\text { pro Minute }\end{array}$ & $\begin{array}{c}\text { Für } 1 \mathrm{mkg} \\
\text { Steigarbeit } \\
\text { cal. umgesetzt }\end{array}$ \\
\hline $\begin{array}{l}33 \mathrm{a} \\
35 \mathrm{a} \\
36 \mathrm{a} \\
40 \mathrm{a}\end{array}$ & 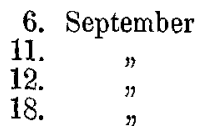 & $\begin{array}{l}34,82 \\
37,61 \\
35,75 \\
35,07\end{array}$ & $\begin{array}{r}9,59 \\
10,36 \\
9,85 \\
9,66\end{array}$ & $\begin{array}{l}9,653 \\
9,513 \\
9,062 \\
9,639\end{array}$ \\
\hline
\end{tabular}

Tabelle X.

Versuchsstrecke I. Steigung 26,5\% im Mittel.

\begin{tabular}{|c|c|c|c|c|}
\hline Nr. & Tag & $\begin{array}{c}\text { Weg } \\
\text { pro Minute }\end{array}$ & $\begin{array}{l}\text { Steigung } \\
\text { pro Minute }\end{array}$ & $\begin{array}{l}\text { Für } 1 \mathrm{mkg} \\
\text { cal. umgesetzt }\end{array}$ \\
\hline $\begin{array}{l}33 \mathrm{~b} \\
35 \mathrm{~b} \\
36 \mathrm{~b} \\
40 \mathrm{~b}\end{array}$ & $\begin{array}{lc}\text { 6. } & \text { September } \\
\text { 11. } & n \\
12 . & n \\
18 . & "\end{array}$ & $\begin{array}{l}35,91 \\
37,29 \\
35,92 \\
35,65\end{array}$ & $\begin{array}{l}9,27 \\
9,63 \\
9,27 \\
8,94\end{array}$ & $\begin{array}{l}9,735 \\
9,123 \\
8,913 \\
9,117\end{array}$ \\
\hline
\end{tabular}

Die Tabellen IX, X, XI und XII bedürfen keiner weiteren Besprechung mehr. Sie lösen das Bild der Tab. VIII in das der einzelnen Versuchs- 
reihen auf und lassen das in dieser in Mittelwerten dargestellte Verhalten in den Einzelwerten die zur Beobachtung gelangten erkennen.

$$
\text { Tabelle XI. }
$$

Versuchsstrecke III. Steigung $20,2 \mathrm{im}$ Mittel.

\begin{tabular}{|c|c|c|c|c|}
\hline $\mathrm{Nr}$. & Tag & $\begin{array}{c}\text { Weg } \\
\text { pro Minute }\end{array}$ & $\begin{array}{c}\text { Steigung } \\
\text { pro Minute }\end{array}$ & $\begin{array}{c}\text { Für } 1 \mathrm{mkg} \\
\text { Steigarbeit } \\
\text { cal. umgesetzt }\end{array}$ \\
\hline $\begin{array}{l}33 \mathrm{c} \\
35 \mathrm{c} \\
36 \mathrm{c} \\
40 \mathrm{c}\end{array}$ & $\begin{array}{l}\text { 6. } \\
\text { 11. September } \\
12 . \quad " \\
18 . \\
18 .\end{array}$ & $\begin{array}{l}36,59 \\
35,56 \\
34,90 \\
35,18\end{array}$ & $\begin{array}{r}10,03 \\
9,75 \\
9,59 \\
9,65\end{array}$ & $\begin{array}{l}8,945 \\
9,097 \\
8,750 \\
9,015\end{array}$ \\
\hline
\end{tabular}

Tabelle XII.

Versuchsstrecke 1V. Steigung $27 \%$ im Mittel.

\begin{tabular}{|c|c|c|c|c|}
\hline $\mathrm{Nr}$. & $\mathrm{Tag}$ & $\begin{array}{c}\text { Weg } \\
\text { pro Minnte }\end{array}$ & $\begin{array}{c}\text { Steigung } \\
\text { pro Minute }\end{array}$ & $\begin{array}{l}\text { Für } 1 \mathrm{mkg} \\
\text { cal. umgesetzt }\end{array}$ \\
\hline $\begin{array}{l}33 \mathrm{~d} \\
35 \mathrm{~d} \\
36 \mathrm{~d} \\
40 \mathrm{~d}\end{array}$ & $\begin{array}{l}\text { 6. } \\
\text { 11. September } \\
12 . \quad " \\
18 .\end{array}$ & $\begin{array}{l}40,60 \\
40,29 \\
38,21 \\
36,23\end{array}$ & $\begin{array}{r}10,52 \\
10,43 \\
9,90 \\
9,38\end{array}$ & $\begin{array}{l}9,160 \\
9,069 \\
8,801 \\
8,864\end{array}$ \\
\hline
\end{tabular}

Es wurde oben die Frage erörtert, inwieweit der Alkohol überhaupt, angenommen, er könne zur Leistung von Muskelarbeit isodynam mit den Nahrungsmitteln verwendet werden, als Kraftspender für nutzbare Arbeit in Betracht zu ziehen sei, und wieviel von ler zugeführten Menge im vorliegenden Falle bätte ausgegeben werden müssen, nur um die geschaffenen Mehrauslagen zu decken. Ob Alkohol in unseren Versuchen aber wirklich als Quelle von Muskelkraft direkt oder indirekt zur Ausnützung gelangte, oder ob er nur nutzlos als Brennstoff verbrannt worden sei, um aus den Körper eliminiert zu werden, haben wir daselbst nicht entschieden, dagegen an anderer Stelle bei Besprechung der respiratorischen Quotienten hervorgehoben, dass deren Verhaltẹn die Annahme einer Sparwirkung des Alkohols berechtigt erscheinen lässt und den Schluss gestattet, dass Alkohol direkt oder indirekt für die Leistung der Arbeit herangezogen wurde.

Man kann versuchen, der Frage näherzutreten, muss dabei aber von einer Voraussetzung ausgehen, für die wir nur einen Wahrscheinlichkeitsbeweis haben: dass in der Zeit von der Einnahme der 
Alkoholdosis bis zum Ende des letzten Aufwärtsmarsches, also im Verlaufe von nicht ganz 4 Stunden, in denen eine gesamte Arbeit von rund $190000 \mathrm{mkg}$ geleistet wurde, aller zugeführte Alkohol zur Verbrennung gelangte ${ }^{1}$ ), beziehungsweise der Rest, der zu dieser Zeit noch nicht verbrannt sein sollte, sich in der anschliessenden Ruheperiode isodynam mit den Nahrungsmitteln verhalten hatte, wie dies durch Atwater am Respirationskalorimeter festgestellt wurde. Da dieser eventuelle Rest, dessen Grösse wir nicht kennen, der auch ganz fehlen kann, sich in der Ruhe wie ein Nahrungsmittel verhält, daher im Stoffwechselversuch direkt als solches zu rechnen. ist, können wir seinen Wert auch einem Nahrungsmittelanteil, der während des Aufstieges verbraucht wurde, sei dies nun Fett oder Kohlehydrat gewesen, isodynam einsetzen. Wir begehen daher keinen Fehler, wenn wir sämtliche Kalorien, die der Verbrennung des. Alkohols entsprechen, als in der Arbeitszeit verausgabt ansprechen, da der möglicherweise noch unverbrannte Rest seinem Brennwert nach zum Beispiel einen Teil des Ruheverbrauches, der der ganzen Arbeitszeit zugrunde liegt, hätte decken können, jedenfalls aber als Ersatz für eine kalorisch gleichwertige Menge eines Nahrungsmittels anzusetzen ist. Noch weiter müssen wir eine Vereinfachung einführen, die uns den Uberblick erleichtern solll. Wir wollen der Betrachtung die reine Marschzeit zugrunde legen, somit mit $3^{\mathrm{h}} 05^{\prime}=185 \mathrm{Min}$. im Mittel rechnen unter Ausserachtlassung der Zeit vor dem Abmarsch. Es ist ja gewiss nicht bewiesen, dass in dieser allerdings nur mit geringer Körperarbeit bedingten halben Stunde kein Alkohol verbrannt wurde, ja geradezu unwahrscheinlich, dies anzunehmen, auch bin ich mir voll bewusst, dass in die erste Zeit des Anstieges die "Reizwirkung" des Alkohols gefallen sein muss, die erst gesondertem Studium zugeführt werden wird, so dass eine Voraussetzung, wie wir sie machen, mit den Tatsachen in Widerspruch steht; nichtsdestoweniger wird sie uns aber doch ein Überblick, den wir unter diesen künstlich schematisierten Verbältnissen gewinnen, gestatten und ermöglichen, zu entscheiden, ob Alkohol für die Leistung von Muskelarbeit verbrannt wurde oder nicht, denn nur um diese Frage soll es sich hier handeln, da ein Eingehen in die quantitativen Verhältnisse unter den Voraussetzungen, die zu machen waren, nicht gestattet wäre und auch zu keinem Resultat führen würde.

1) Siehe oben S. 382 . 
Nehmen wir das Mittel der Alkoholzufuhr aus dem letzten und vorletzten Versuch (36 und 40) mit $35 \mathrm{ccm}=30 \mathrm{~g}$ (rund) Alkohol entsprechend 7070 cal. per Gramm an, so entspricht dies 212,100 cal. Brennwert, oder bei einer Verbrennung im Verlauf von 185 Minuten einer durchschnittlich per Minute erzeugten Verbrennungswärme von 1146 cal. Wäre der Alkohol nutzlos verbrannt worden, auch ohne an den Verbrennungsvorgängen, die für nutzlose Muskelarbeit geleistet wurden, teilzunehmen, so müsste der im Normalversuch verausgabte Wert an Kalorien für dieselbe Arbeit per Minute um den Verbrennungswert des Alkohols erböht jenem Verbrennungswert entsprechen, der dann im Alkoholversuch zustande gekommen wäre.

Die Gesamtansgabe an Kalorien für dieselbe Arbeit, die im Alkoholversuch in drei Stunden fünf Minuten geleistet wurde, beträgt für den Normalversuch rund $160 \times 10000=1600000$ cal.; somit ist bezogen auf dieselbe Versuchszeit wie in den Versuchen 36 und 40 , per Minute ein Umsatz von 8648 cal. erforderlich, bestritten aus den Kalorien der gewöhnlichen Nahrung anstatt der tatsächlich aufgewendeten 8995 eal. per Minute im Alkoholversuch, die wir nicht glattweg auf eine geringere Ausnützung der Nahrungsstoffe verlegen dürfen, sondern vor allem als bedingt durch die Nebenarbeit und durch Ungeschicklichkeit ansehen müssen. Addiert man zu dem aus dem Normalversuch auf die Minute berechneten Verbrauch, wobei die Zeit des Alkoholversuchs zugrunde gelegt ist, die der nutzlosen Verbrennung von Alkohol entsprechende Zabl von 1146 cal., so erhalten wir einen Verbrennungswert von 9794 cal. per Minute, der tatsächlich im Alkoholversuch nicht annäherud erreicht wurde, sondern $9 \%$ höher liegt, als für diesen der Wahrheit entspricht, wobei wir allerdings die Ausscheidung von unverbranntem Alkohol, die die Verhältnisse wegen ihrer Geringfügigkeit nicht ändert, nicht berücksichtigt haben.

Nur auf einen Punkt müssen wir hier noch hinweisen. Wir haben oben, als wir den Einfluss des respiratorisehen Quotienten besprachen, darauf hingewiesen, dass wir schlechtweg annehmen, es sei nicht Alkohol, sondern nur Fett und Kohlehydrat verbrannt, wie es der Auffassung entsprach, die ich bei der Durchführung und Berechnung der Versuche noch hatte. Legen wir nun dieselbe Voraussetzung, die wir hier machten, dass der gesamte Alkohol während des Marsches verbrannt sei, einer Berechnung zugrunde, so haben 
wir unter der Annahme, die Verbrennung des Alkohols sei auf der ganzen Versuchsstrecke gleichmässig erfolgt, zu den zwei Gleichungen mit drei Unbekannten noch eine dritte Gleichung und können. nun tatsächlich die Grösse der Verbrennung von Fett und Kohlehydrat von jener des Alkohols sondern und angeben, um wieviel wir den Brennwert des Sauerstoffes zu niedrig eingesetzt haben. Es wurden $30 \mathrm{~g}$ Alkohol im Mittel in 185 Minuten verbrannt, auf die Minute trifft also eine Oxydation von $0,166 \mathrm{~g}$ Alkohol. Da für ein Gramm zur Verbrennung 1,46 Liter Sauerstoff erforderlich sind, wurden für die $0,166 \mathrm{~g}$ verbraucht 0,242 Liter Sauerstoff; diese haben wir für die Verbrennung von Fett in der Berechnung in Anspruch genommen. Da nun 1 Liter Sauerstoff bei Fettverbrennung 4,686 Cal. entspricht, bei Alkoholverbrennung aber 4,843, so haben wir pro Liter Sauerstoff, der Alkobol anstatt Fettverbrennung entspricht, 0,157 Cal. oder 157 cal. zu wenig angesetzt; für die pro Minute für die Alkoholverbrennung verbrauchte Sauerstoffmenge sind daher $0,242 \times 157=37,99$ cal. zu wenig in Anschlag gebracht worden, so dass wir den Umsatz pro Minute im Alkoholversuch anstatt mit 8995 richtiger mit 9033 cal. zu berechnen hätten, wodurch sich der abgerundete Wert von $9 \%$ ebenfalls nicht ändert $(8,9 \%$ auf $8,5 \%)$.

Es ändert sich aber auch am ganzen Bilde gar nichts, wenn wir der Grösse des zur Verbrennung gelangten Alkohols in anderer Weise Rechnung tragen und dazu Versuch 40 , in dem $40 \mathrm{ccm} \mathrm{Al-}$ kohol genossen wurden, für sich gesondert ins Auge fassen.

Die $40 \mathrm{~cm}=32,16 \mathrm{~g}$ Alkohol wurden in 190 Minuten verausgabt, so dass auf die Minute eine Verbrennung von $0,169 \mathrm{~g}$ Alkohol und eine Produktion von $0,169 \times 7070=1194,8$ cal. aus Alkohol entfällt; dabei mussten $245,9 \mathrm{ccm}$ Sauerstoff verbraucht und $163,9 \mathrm{ccm}$ Koblensäure produziert worden sein. Ziehen wir diese letzteren beiden Werte von den Mitteln des Sauerstoffverbrauches und der Kohlensäureprodultion bei der Arbeit ab, so erhalten wir 1862,5-245,9= $1616,6 \mathrm{~cm} \mathrm{O} \mathrm{O}_{2}$-Verbrauch und $15060-1639=13421 \mathrm{ccm} \mathrm{CO}_{2}$ Produktion für die Verbrennung von Fett und Kohlehydrat; dadurch ergibt sich aber auch ein neuer Arbeitsquotient von 0,83 , nach dem wir nun die bei der Verbrennung von Fett und Kohlebydrat entwickelte Energie mit $4,838 \times 1616,6=7823$ cal. berechnen. Hierzu haben wir den Wert aus der Verbrennung der $0,169 \mathrm{~g}$ Alkohol zu addieren, wodurch das Mittel der für die Arbeit verausgabten Kalorien 
in Versuch 40 Tab. I sich von 8973 cal. auf 9018 cal. per Minute erhöht. Gegenüber dem Wert von 9841 cal., den wir erhalten müssten, wenn wir annehmen wollten, der Alkohol sei in seiner Gänze nutzlos verbraucht worden, wie dies auf der vorigen Seite auch für das Mittel von Versuch 36 und 40 ausgeführt wurde, bleibt auch hier der wahre gefundene Wert immer noch um mehr als $8 \%$ zurück.

Es ist also tatsächlich der Umsatz im Alkoholversuch per Minute um fast dreiviertel des Brennwertes des Alkohols hinter dieser Grösse zurückgeblieben, was um so mehr hervorzuheben ist, als die Arbeitsleistung im Alkoholversuch eine grössere war als im Normalversuch, wenn wir die ungeschicktere Muskelbewegung berücksichtigen.

Muss es demnach, wie dies bereits aus den respiratorischen Quotienten hervorging, mögen die Voraussetzungen, die wir machen mussten, das Bild noch so sehr entstellen, als ganz ausgeschlossen angesehen werden, dass Alkohol nur verbrennt, ohne dass sein Brennwert im Organismus nicht zum Teil nutzbar verwertet wird, so vermögen wir nicht $\mathrm{zu}$ entscheiden, in welchem Umfange er sich als Kraftquelle an der Muskelarbeit beteiligt hat, da der Ruheverbrauch für mich im Mittel 1173 cal. pro Minute beträgt, also fast ebenso hoch ist wie die Zahl der Kalorien, die aus der Verbrennung des Alkohols unter unseren Voraussetzungen per Minute zur Verfügung stehen würde, so kann wobl ohne ein allzugrosses Wagnis darauf auch der Schluss aufgebaut werden, der in Übereinstimmung mit der Änderung der respiratorischen Quotienten steht, dass auch, falls ein namhafter Betrag des verbrannten Alkohols zur Deckung des Energiebedarfes für den den Arbeitsversuchen zugrunde liegenden Ruhewert verausgabt worden wäre, dieser Betrag doch nie eine solche Höhe hätte erreichen können, dass nicht ein restlicher Anteil des kalorischen Wertes des verbrannten Alkohols noch für die Bestreitung von Ausgaben für die Muskelarbeit herangezogen werden musste. Aufgabe weiterer Untersuchungen wird es sein, besonders unter der Zergliederung der einzelnen Perioden der Wirkung des Alkohols und unter Festlegung der zeitlichen Verhältnisse der Verbrennung der zugeführten Alkoholmengen aus den voranstehend hypothetiseh aufgebauten Folgerungen durch Zahlen gestützte Tatsachen $\mathrm{zu}$ formen, wobei jch hoffe, besonders durch die Untersuchung von Personen, die an reichlichen Alkoholgenuss gewöhnt sind und trotzdem schwere Arbeit verrichten, aber auch durch Tierexperimente genauere Auf- 
schlüsse zu erhalten, welch letztere besonders über die zeitlichen Verhältnisse der Verbrennung des Alkohols bei Ruhe und Arbeit Aufschlüsse versprechen, so dass es dann möglich sein wird, die vielen Lücken, die in den vorliegenden Versuchen offen gelassen werden mussten, wenigstens teilweise zu füllen.

Überblicken wir die Ergebnisse der Versuche, so begegnen wir bei einer an mässige Alkoholgaben gewöhnten Versuchsperson nach Zufuhr von $30 \mathrm{~g}$ Alkohol einer Reihe ganz gesetzmässiger Wirkungen. Wir finden einen innigen Zusammenhang mit den Versuchen von Chaureau.

Waren es auch sehr grosse Dosen, die dort dem Tier verabfolgt wurden, so stimmt das von $\mathrm{Ch}$ a u veau festgelegte Gesamtbild eindeutig mit den Resultaten der vorliegenden Marschversuche überein; das, was Chauveau im ganzen am Tiere beobachten konnte, geben die Versuche auf der Sporner-Alpe in feiner, zergliederter Form wieder. Wir fanden, ebenso wie $\mathrm{Ch}$ a u ve a $\mathrm{u}$, die Abnahme der Leistungsfähigkeit und die Steigerung des Umsatzes.

Gewiss hat Rosemann bei der Beurteilung der Chauveauschen Versuche recht, wenn er in ihnen keinen Beweis gegen die Annahme findet, dass die Energie des Alkohols bei Muskelarbeit verwertet werden könne und mit vollem Recht leitet er aus dem respiratorischen Quotienten die Verbrennung von Alkohol ab und tritt für die Ansicht ein, dass der beduselte Hund nur unter ungleich grösseren Ausgaben seine Muskelarbeit leisten konnte, die einen solchen Aufwand erforderte, dass nicht bloss der ganze Überschuss an Nahrung hierfür verbraucht wurde, sondern noch ein Plus zugesetzt werden musste. Wenn wir an den vorliegenden Versuchen sehen, wie bedeutend die Änderungen in Aufwand von Energie und in der Leistung sein können, ohne dass die Alkoholdosis auch nur einigermassen merkliche subjektive Symptome auslöste, so darf der grosse Stoffumsatz des Chauveau'schen Hundes nicht in Erstaunen versetzen.

Die Versuche auf der Sporner Alpe ergeben für die Versuchsperson ein Absinken des Effektes um $20 \%$, neben einer gleichzeitigen Verminderung des Wirkungsgrades um 13\%, also geringere Leistung bei grösserem Verbrauch unter Alkoholwirkung, wobei hervorgehoben 
wurde, dass diese Zahlen nicht ohne weiteres auf andere Personen und Verhältnisse übertragen werden dürfen.

Die Ursache für den grösseren Verbrauch ist jerenfalls zu einem grossen Teil in ungeschickterer Muskeltätigkeit und schlechterer Ausnutzung der Wegverhältnisse gegeben, so dass die Art des Marsches nach Alkoholgenuss sich an die Märsche bei geringerer Übung in der ersten Versuchsperiode anschliesst.

Die Gesamt-Verbrennungswärme des zugeführten Alkohols ist grösser als jene der dureh den Alkoholgenuss hervorgerufenen Mehrausgabe für die Gesamtleistung, so dass ein Teil der Energie des zugeführten Alkohols unter der Voraussetzung, dass er zur Leistung nutzbarer Arbeit verwertet werden kann, bei dieser eine Ersparnis an Nahrungsmitteln herbeiführen kann.

Der Alkohol ist für die Versuchsperson trotzdem kein verwertbares Nahrungsmittel bei der Leistung von Steigarbeit, da die Mengen, welche zur Leistung einer einigermassen bemerkenswerten Arbeit von ihr genossen werden müssten, so gross sind, dass sie bei längere Zeit hindurch fortgesetzter Zufuhr zu sebweren Störungen im Organismus führen müssten. Ausserdem vermochte die Versuchsperson auf Grund von Energie, die den gewöhnten Nahrungsmitteln entstammen, dieselbe Arbejtslejstung in kürzerer Zeit und bei geringerem Verbrauch zu leisten, als wenn Alkohol der Nahrung zugesetzt wurde.

Es wurde während des Marsches nicht nur Alkohol verbrant, sondern wir sind auch berechtigt anzunehmen, dass zum mindesten ein Teil der dadurch verfügbar gewordeueri Energie vom Körper ausgenutzt wird und auch zur Leistung von Arbeitherangezogen wird.

Das Verhalten der respiratorischen Quotienten, die im Verlaufe des Marsches nicht wie im Normalversuch einen Abfall zeigen, sondern vielmehr einen ständigen Anstieg oder in manchen Fällen ein Konstantbleiben aufweisen, das bei geringer, verfügbarer Kohlehydratmenge im selben Sinne gedeutet werden muss, $\mathrm{z}$ wing t unter Berücksichtigung der Tatsache, dass die respiratorischen Quotienten am Schlusse des Aufstieges im Alkoholversuch eine Höhe aufweisen, die jene im ent- 
sprechenden Kontrollversuch übertrifft oder sogar eine Grösse des Wertes zeigen, wie er sonst im Beginne des Aufstieges gefunden wird, zur Annahme, dass nicht nur Alkohol während des Aufstieges verbrannt wird, sondern durch dessen Verbrennung ein Ersparnis an Kohlehydrat erzielt wird, also Arbeit direkt oder indirekt auf Grund von Verbrennug von Alkohol geleistet wird.

Berechnet man den Energieumsatz per Minute aus den Ausgaben im Normalversuch für den ganzen Marsch und zwar für jene Geschwindigkeit, die in den Versuchen nach Alkokolgenuss erreicht wurde, und addiert man hierzu jene Verbrennungswärme, die sich im Mittel für die Oxydation des zugeführten Alkohols per Minute ergeben würde, so erhält man einen um $9 \%$ höheren Energieumsatz, als er tatsächlich in den Versuchen nach Alkoholgenuss beobachtet wurde, so dass es ausgeschlossen ist, wie auch aus dieser Form der Rechnung hervorgeht, dass der Alkohol bei der Marscharbeit nutzlos, nur um eliminiert zu werden, verbrannt wird; er muss zu Deckung eines Teiles der Ausgaben während des ganzen Anstieges herangezogen werden; dieser ist so gross, dass es nicht annehmbar erscheint, ihn allein für die Bestreitung der Ausgaben für den den Arbeitsversuchen zugrunde liegenden Ruhewert anzusehen, woraus sich neuerdings der Schluss ergibt, dass Alkohol wenigstens zu einem Teile Nahrungsstoffe bei der Lieferung der Energie für die Muskelarbeit vertreten könne.

Im Laufe jeder Versuchsreihe war eine Abnahme der Giftwirkung des Alkohols zu beobachten, die sich in einem Ansteigen des Effektes und einem Absinken des Verbrauches trotz des grösseren Effektes kundgibt.

Die nacheinander durchgeführten Versuchsreihen lassen eine Gewöhnung an die Giftwirkung des Alkohols erkennen, die in jener Periode, in der diese am ausgesprochensten ist, sich auch am deutlichsten bebemerkbar macht.

Ein geringes Ansteigen der Alkoholdosis (von $30-40 \mathrm{cem}$ ) lässt zwar die entstandene Gewöhnung als eine teilweise noch erkennen, führt aber neuerdings ein Absinken von Effekt und Wirkungsgrad herbei. 
Beiträge zur Physiologie des Menschen im Hochgebirge. III. $\quad 399$

Eine Reihe von Fragen, die mit der Bearbeitung dieser Versuche in direktem Zusammenhang steht, konnte mangels an Zeit wegen der ungünstigen Witterungsverhältnisse nicht durchgeführt werden und soll weiteren Versuchen vorbehalten sein; so werden besonders die Untersuchungen über die Arbeitsleistung des an starken Alkoholgenuss gewöhnten Menschen, jene über die zeitlichen Verhältnisse der Verbrennung und Ausscheidung des Alkohols und über das Verhalten in der ersten und den späteren Perioden nach der Zufuhr an Alkohol bei Körperruhe, hauptsächlich aber bei Arbeit erst durchzuführen sein, um viele der Ergebnisse, die hier auf noch nicht genügend fundierter Basis aufgestellt sind, als bewiesen ansehen zu können. 